\title{
BDNF Driven Coupling Between KCC2 Downregulation and Fyn-Dependent Phosphorylation of GluN2B NMDA Receptors in Human Spinal Pain Processing
}

\author{
By \\ Chaya Kandegedara \\ Master
in \\ Neuroscience \\ Carleton University \\ Ottawa, Ontario \\ (C) 2019 \\ Chaya Kandegedara
}

A thesis submitted to the Faculty of Graduate and Postdoctoral Affairs in partial fulfillment of the requirements for the degree of 


\begin{abstract}
$\underline{\text { Abstract }}$
Hyperexcitation of neurons in the dorsal horn of the spinal cord leads to chronic pain. In rodent pain models, the neurotrophic factor BDNF mediates loss of inhibitory signalling. This permits enhancement of excitatory GluN2B-NMDAR currents in lamina I neuronal synapses. However, whether this pathway is conserved between rodents and humans as well as between sexes is unknown. We developed a human ex vivo BDNF model of pathological pain using postmortem human spinal tissue. We found that ex vivo BDNF downregulates $\mathrm{KCC} 2$ and active STEP $_{61}$ and upregulates active Fyn and phosphorylated GluN2B at the superficial dorsal horn in both human and rodent males. We also show that BDNF increases intracellular KCC2 of superficial dorsal horn neurons. Thus, our human model may connect the vast translational divide between rodent and human chronic pain mechanisms to identify and validate new therapeutic targets for human chronic pain.
\end{abstract}




\section{$\underline{\text { Acknowledgements }}$}

Thank you to Dr. Michael Hildebrand for his continued guidance, encouragement and endless supply of jelly bellies throughout my time in the Hildebrand lab. Thank you to Dr. Eve Tsai, OHRI and TOH research facilitators and operating room staff for helping us with human spinal cord collection. Thank you to collaborators from the De Koninck and Lombroso labs. Thank you to Annemarie Dedek for keeping me company on long nights at the hospital when we had spinal cord donors. Thank you to Teresa Fortin for sharing her expertise, protocols and lots of antibodies with me. Thank you to Tina Wang and Alysia Ross for the enjoyable coffee breaks between experiments. Thank you to my parents for feeding me lots and my brother for letting me use his comfortable chair (without complaining) when I was writing my thesis. Very big thank you to Zach Dwyer for his continued feedback and for the many hours he spent teaching me all the techniques required for my experiments. And thank you to everyone I woke up at the crack of dawn to ask for a ride to the hospital. 


\section{Table of contents}

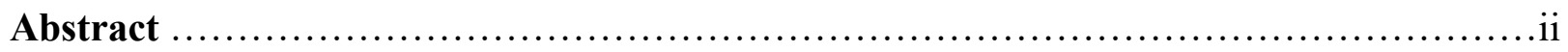

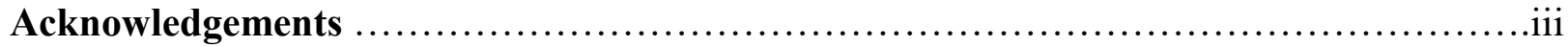

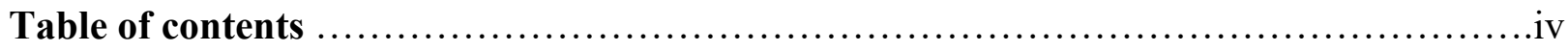

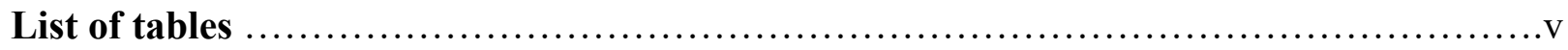

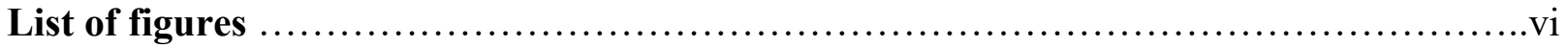

\section{Introduction}

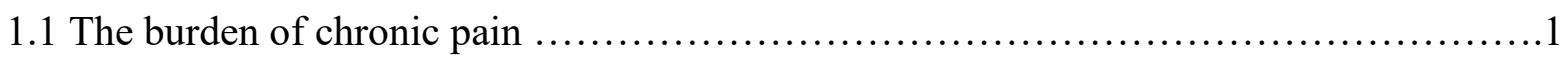

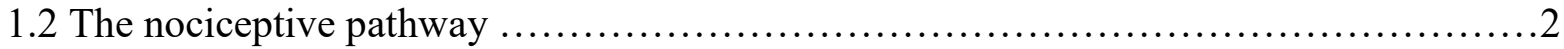

1.3 Spinal cord lamina I and central sensitization in pain transmission ................. 4

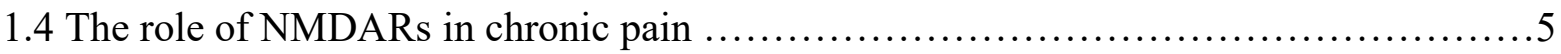

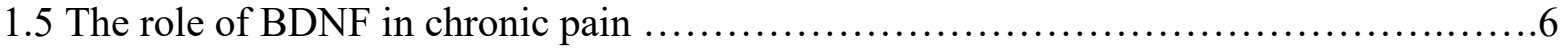

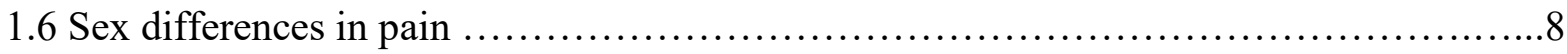

1.7 BDNF potentiates NMDARs through loss of inhibition ...........................

1.8 STEP $_{61}$ - the linker between disinhibition and increased excitation $\ldots \ldots \ldots \ldots \ldots \ldots \ldots . \ldots 11$

1.9 Translational gap in chronic pain between rodent and clinical experiments ..............11

1.10 GluN2B-NMDARs may contribute to dorsal horn hyperexcitability in humans .........12

1.11 The ex vivo BDNF pathological pain model .........................................13

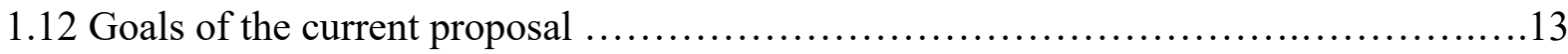

\section{Experimental procedure}

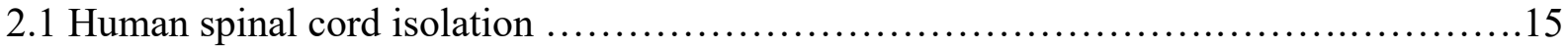

2.2 Human ex vivo BDNF model of pathological pain ................................. 15

2.3 Isolation of synaptic fractions and biochemical analysis of human spinal tissue ...........16

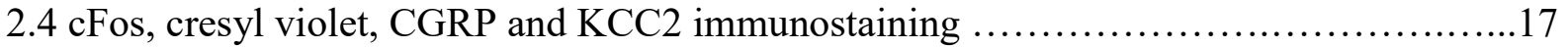

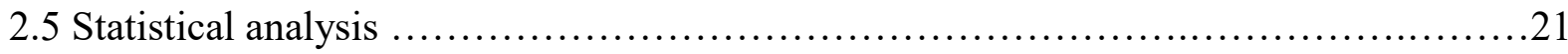

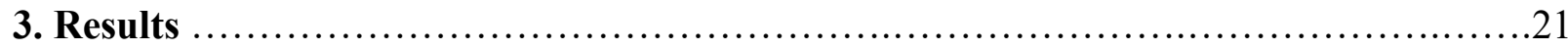

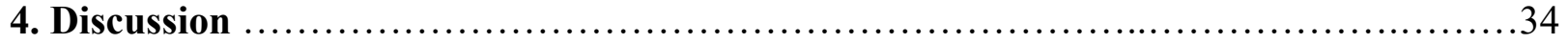

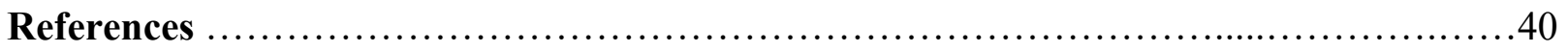




\section{$\underline{\text { List of Tables }}$}

Table 1. Demographics of spinal tissue donors and the experiments performed on the

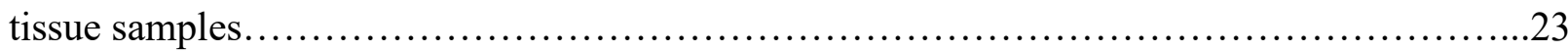




\section{List of Figures}

\section{Figure 1.}

The two mechanisms of BDNF induced superficial dorsal horn neuronal hyperexcitation in chronic pain (page 10)

\section{Figure 2:}

The human ex vivo BDNF model (page 22)

\section{Figure 3:}

Ex vivo BDNF model of spinal pain processing downregulates $\mathrm{KCC} 2$ and $\mathrm{STEP}_{61}$ and upregulates pFyn and pGluN2B in the superficial dorsal horn synapses of adult male human spinal cord tissue (page 25)

\section{Figure 4:}

Ex vivo BDNF model of spinal pain processing does not show significant changes in $\mathrm{KCC} 2$, $\mathrm{STEP}_{61}, \mathrm{pFyn}_{\mathrm{n}}$ and $\mathrm{pGluN2B}$ in the superficial dorsal horn synapses of adult female human spinal cord tissue (page 26)

\section{Figure 5:}

Ex vivo $\mathrm{BDNF}$ treatment induced a significant decrease in $\mathrm{KCC} 2$ expression at neuronal membranes with an associated increase in intracellular KCC2 expression in human male (page 27)

\section{Figure 6:}

CGRP expression specific to the nociceptive peptidergic afferent terminals in the superficial dorsal horn lamina I and outer lamina II (page 28)

\section{Figure 7:}

CGRP staining was used to demarcate the superficial dorsal horn region (page 29)

\section{Figure 8:}

cFos staining patterns match Cresyl violet positive cell distribution (page 30)

\section{Figure 9:}

cFos negative stain showed no distinct background staining produced by the secondary antibody and $\mathrm{DAB}$ reaction (page 30 )

\section{Figure 10:}

Representative images show high individual variability in cFos expression in (A) male and (B) female cFos stained BDNF- or saline- treated superficial dorsal horn (page 32)

\section{Figure 11:}

cFos expression increases in BDNF-treated male superficial dorsal horn but not in female BDNFtreated superficial dorsal horn. (page 33) 


\section{Introduction}

\subsection{The burden of chronic pain}

Chronic pain is a global issue. About $20 \%$ of the global adult population and $20 \%$ of Canadian adults are affected by a multitude of chronic pain conditions manifested as but not limited to rheumatoid arthritis, cancer pain and lower back pain [1,2]. To add to this issue, there are currently limited safe and effective treatment options for chronic pain. Long-term use of the available medications are often associated with significant side effects including the risk of dependence and overdosing (from opioids), gastrointestinal bleeding and cardiovascular complications [3-6]. The physical and financial disabilities take a toll on the mental health of these individuals, which is indicated by the high comorbidity of chronic pain with depression, substance abuse and anxiety disorders [7]. The coexistence of chronic pain and mental health problems tend to further increase the severity of both conditions [8]. Although a significant amount of primary care practitioners' time is spent on these patients, many of the patients still do not improve symptoms [9]. Thus, the physical, emotional and financial disability that is tightly associated with chronic pain results in producing the lowest quality of life compared to other chronic diseases, leading to a lifetime of suffering [2]. Therefore, there is a significant demand for more effective therapeutics to treat chronic pain. 


\subsection{The nociceptive pathway}

The International Association for the Study of Pain (IASP) defines pain as "an unpleasant sensory and emotional response associated with actual or potential tissue damage". The process by which the nervous system encodes noxious stimuli is known as nociception (IASP). Pain is termed nociceptive when it is caused by the activation of nociceptors by actual/potential damage to non-neural tissue, inflammatory when it is generated by tissue injury and/or immune cell activation, neuropathic when it is produced by a lesion/disease to the central and/or peripheral somatosensory nervous system and nociplastic when pain arises without any apparent actual or potential tissue damage that activates peripheral nociceptors or without a disease/lesion to the somatosensory system (IASP). Complex communication between sensory, emotional and behavioural modalities give rise to pain perception. Acute pain is protective as it drives individuals to avoid harmful environmental stimuli such as extreme temperatures, chemicals and mechanical insults that may cause tissue damage or life-threatening injuries [10]. Similarly, nociception signals an organism of internal events that may require prompt attention. All in all, pain inputs associated with injury facilitate protective behaviour for faster recovery of injured tissue [11].

The nervous system - which is the network that consists of the brain, spinal cord and nerves that acquire, interpret and respond to external and internal stimuli - is critical for pain transmission. Several processes mediate acute pain processing [12]. When peripheral nerve endings of sensory neurons (nociceptors) are stimulated by strong noxious stimuli, the depolarizing receptor potentials reach threshold for action potential firing in the nociceptor. Inflammation caused by the injury further sensitizes the injury site by releasing prostaglandins, substance $\mathrm{P}$, bradykinin, serotonin and histamine - a process collectively known as "peripheral sensitization" [13]. These 
inflammatory agents modulate pain by promoting redness, swelling, hyperalgesia (heightened pain sensitivity to a normally pain producing stimuli) and allodynia (increased sensitivity to previously non-painful stimuli) $[12,14]$. Pain signals from nociceptor stimulation and inflammation are conducted towards the spinal cord via two types of nerve fibers. Localized sharp pain signals are conducted through A $\delta$ fibers, which are responsible for the "fast pain" response. For example, these fibres are responsible for the very fast pain signals that produces a withdrawal response when one steps on a nail. In the 'slow pain" response, non-localized burn and ache signals from the injured region that lasts for a prolonged period of time are carried via non-myelinated c-fibers [15, 16]. The difference in speeds at which actions potentials travel through these fibers explains the short-lived region-specific pain that transitions to a more dull and dispersed pain [16]. Also, the dull, slow, burning and aching pain in chronic pain is transmitted via c-fibers. The transmission of pain signals is facilitated by several neurotransmitters including glutamate, norepinephrine, dopamine, serotonin and substance $\mathrm{P}$ at three major junctions of the nervous system $[17,18]$. Signals first travel from nociceptors to the dorsal horn of the spinal cord, then to the thalamus and brainstem from the dorsal horn and finally from the thalamus to the cerebral cortex. Pain perception occurs when the thalamus conveys pain signals to brain regions such as the limbic system, periaqueductal gray area and other regions that produce sensation, emotions, stress, behaviour, and motor and autonomic responses [19]. The perception of pain as an emotionally unpleasant event is brought about by the combination of the outputs from these brain regions.

\subsection{Spinal cord lamina I and central sensitization in pain transmission.}

The dorsal horn of the spinal cord receives and processes all somatosensory information, including pain signals, which are then transmitted to the brain. Pain signals are relayed to specific 
laminae of the dorsal horn. Myelinated A $\delta$ fibers synapse at laminae I and V and unmyelinated cfibers synapse at superficial lamina I and outer part of lamina II [19]. The peptidergic subtype of c-fibers are known to be relevant in pain. This subtype releases several neuropeptides including calcitonin gene related peptide (CGRP) [20]. The most superficial lamina I of the dorsal horn is a key region for pain transmission as this region consists of the majority of projection neurons that convey pain signals to the brain [21]. These neurons project to brain regions that contribute to sensory-discriminative and affective-motivational components of pain [21]. Excitatory glutamatergic and inhibitory GABAergic and/or glycinergic interneurons make up $90-95 \%$ of the neuronal population within the lamina I region $[22,23]$. These interneurons modulate the transfer of information to the projection neurons and reflex pathways [21].

Although acute pain is a protective mechanism, chronic pain lacks any adaptive value for the sufferer. In some cases, pain can last even weeks to years after the initial injury is healed. Repeated noxious stimulation of nociceptive afferents from the initial injury modifies normal pain processing in the spinal cord making the individual more sensitive to pain - which is seen in allodynia, hyperalgesia as well as spontaneous pain in the absence of sensory input [24]. This modification is termed central sensitization and refers to the potentially long-lasting plastic changes that occur in the lamina I region that contributes to the establishment and maintenance of dysfunctional pain processing [24]. The tendency to develop central sensitization is higher if the pain is severe and lasts for a prolonged period [12]. Central sensitization is well investigated in rodent models, and pain researchers postulate that same causes underlie human chronic pain states as well. However, further studies are required to elucidate the unique spinal mechanisms of human chronic pain. 


\subsection{The role of NMDARs in chronic pain}

Glutamatergic NMDA receptors (NMDARs) are essential for synaptic plasticity, learning, memory as well as pathological mechanisms of pain in the dorsal horn of the spinal cord $[25,26]$. A high concentration of NMDARs is found in the superficial dorsal horn [27]. NMDARs consist of two GluN1 subunits and a combination of two of the four GluN2 subunits: GluN2A, GluN2B, GluN2C or GluN2D subunits [28]. In acute pain, glutamate - which is the primary excitatory neurotransmitter of the nervous system - binding to AMPA receptors in dorsal horn neurons initiates action potentials that travel to the brain. However, NMDARs are essential drivers in the transition from acute to chronic pain processing [29]. Continuous AMPA receptor stimulation leads to membrane depolarization which facilitates the removal of the magnesium ion block of NMDARs. The result is sodium and calcium ion influx through the NMDAR receptor channel resulting in excitatory post synaptic potentials [27]. This allows glutamate to activate NMDARs leading to "central windup" [29]. Central windup refers to the escalation of perceived pain intensity caused by repeated stimulation of peripheral c-fibers resulting in progressively increasing dorsal horn neuronal firing [30]. Initially, windup forces one to protect the injured area to allow recovery and these changes resolve with healing. If appropriate pain control measures are not taken, central windup and NMDAR activation can lead to chronic pain.

During pathological inflammatory and neuropathic pain states, there is an upregulation of NMDARs in the spinal cord [31-33]. GluN2B subunits are the predominant GluN2 isoform expressed in laminae I and II, and GluN2B-containing NMDAR responses predominate at lamina I neuronal synapses $[34,35]$. GluN2B subunit is essential for the development of neuropathic pain, 
as blocking GluN2B subunits with a specific antagonist significantly reduces pain behaviour in rodents [36].

Fyn kinase is a Src family tyrosine kinase that phosphorylates and potentiates NMDARs and drives pain hypersensitivity [36, 37]. Fyn kinase preferentially phosphorylates GluN2B subunit at its Tyrosine 1472 residue [36, 38, 39]. Mice lacking Fyn kinase do not develop neuropathic pain compared to the control animals [36]. Phosphorylation of GluN2B potentiates NMDAR currents by increasing NMDAR expression and increasing the duration and probability of NMDAR channel opening [40-42]. Thus, NMDAR phosphorylation contributes to enhanced neuronal excitation [27]. In fact, GluN2B phosphorylation is significantly increased in the superficial dorsal horn in rodents with neuropathic pain [36].

\subsection{The role of BDNF in chronic pain}

Several growth factors are implicated in the regulation of persistent pain [43-46]. Among these, numerous studies using rodent chronic pain models show that Brain Derived Neurotrophic Factor (BDNF) - a protein primarily known to support neuronal survival, neurogenesis, neuronal excitability and synaptic plasticity in the brain - is key for the initiation and maintenance of chronic pain in the spinal cord [47-49]. BDNF is synthesized in the dorsal root ganglion (DRG) which houses cell bodies of sensory neurons. BDNF is then transported and stored in c-fiber terminals at the superficial dorsal horn [50]. BDNF drives both inflammatory and neuropathic pain. BDNF is released during burst firing of primary nociceptor afferents in inflammatory pain [49]. Increases in BDNF is also seen in the dorsal root ganglion neurons in inflammatory pain models. Peripheral inflammation as well as burst firing of primary nociceptive afferents release BDNF in the dorsal horn resulting in behavioural pain hypersensitivity $[43,49,51]$. Complementary upregulation and 
phosphorylation of tropomyosin receptor kinase (TrkB), the high affinity receptors of BDNF, in the post synaptic neurons of the dorsal horn is also seen during c-fiber activation and inflammation $[43,52]$. In neuropathic pain, CNS- resident microglia activated during mechanisms of central sensitization release BDNF within the dorsal horn in male rodents [53]. Intrathecal antibodies to BDNF, as well as TrkB inhibitors and inhibiting tyrosine kinase that phosphorylate TrkB receptors all abolish neuropathic pain in rodents [54]. These studies demonstrate the important role of BDNF-TrkB receptor binding in the development of neuropathic pain. Similarly, pain behaviour induced by inflammation is abolished by the deletion of nociceptor-specific BDNF using a CreloxP system in mice [49]. A recent study by Sikandar et al also showed that BDNF released from sensory neurons is critical for the transition from acute to chronic states of inflammatory as well as some neuropathic pain conditions [55].

Several studies indicate that it is in fact BDNF that increases the activity of GluN2B containing NMDAR via Fyn phosphorylation of Tyr1472 residue [38, 39]. BDNF induced GluN2B phosphorylation is abolished in Fyn knockout rodents [39]. Similarly, patch clamp recordings indicate that Fyn is necessary for the increased NMDAR responses induced by BDNF [56]. In the dorsal horn, the activation of GluN2B-NMDARs by BDNF is important for the development of neuropathic pain [56,57].

\subsection{Sex differences in pain}

Rodent studies show that BDNF signalling pathways in pain are dependent on sex. These findings highlight that male rodents cannot be used to represent pain conditions in females. In males, microglia release BDNF which leads to pain hypersensitivity, however, females most likely depend on other proalgesic substances released by T-lymphocytes of the adaptive immune system 
[53]. Although initial research has focussed on the immune cell involvement in pain, the differences in neuronal processing in pain between the two sexes is unknown. BDNF/TrkB signalling in hyperalgesic priming (a noxious stimuli priming the nociceptive system to respond to a previous innocuous stimuli with long lasting pain hypersensitivity) has been shown to be dependent on sex and species [58]. In this study, researchers used a fusion protein TrkB-Fc to block BDNF activity following an intraplantar injection of IL-6 (noxious priming stimulus). They found that $\mathrm{BDNF} / \mathrm{TrkB}$ signalling is critical for hyperalgesic priming in both male and female rats. However, the mechanism is sex-dependant in mice where priming in male rats was reduced by TrkB-Fc but female mice had no effect. It is unknown whether mice or rats bear more resemblance to human spinal BDNF/TrkB signalling [58]. Therefore, it is necessary to test the pathways of pain signalling in humans tissue to better understand the underlying spinal mechanisms unique to human male and female chronic pain.

\subsection{BDNF potentiates NMDARs through loss of inhibition}

BDNF inhibits GABAergic inhibition (disinhibition) on superficial dorsal horn neurons. $[59,60]$. Disinhibition of dorsal horn neurons is seen in both inflammatory and neuropathic pain [61-63]. Potassium chloride cotransporter 2 (KCC2) removes Cl- from neurons to maintain low concentrations of intracellular Cl- levels [64]. Doing so, KCC2 facilitates GABAergic inhibition on neurons. Disinhibition occurs as a result of BDNF downregulating $\mathrm{KCC} 2$, leading to increased cytosolic $\mathrm{Cl}$ - concentrations. High intracellular $\mathrm{Cl}$ - concentration markedly reduces GABAergic inhibition on the lamina I neurons thereby increasing excitability of these neurons in pathological pain states [65, 66]. A recent study in 2013 used a small organic molecule that restores $\mathrm{KCC} 2$ and its Cl- efflux in an in vivo model of neuropathic pain and found that $\mathrm{KCC} 2$ restoration alleviated 
pain hypersensitivity $[66,67]$. Interestingly, in rodent neuropathic pain as well as in ex vivo BDNF administration, disinhibition by loss of $\mathrm{Cl}-$ is essential for NMDAR potentiation via phosphorylation of the GluN2B subunit at Tyr 1472 [56].

Thus, BDNF binding to TrkB receptors in lamina I neurons results in the loss of balance between excitation and inhibition contributing to increased firing of lamina I neurons sending persistent and spontaneous nociceptive signals to the brain in chronic pain. Downstream markers of neuronal excitability, such as c-Fos, have been used to detect increased activity of the superficial dorsal horn in rodent pain models. c-Fos is an immediate early gene that is typically expressed in the nuclei of neurons immediately following neuronal activation [68]. c-Fos is not usually expressed in the spinal cord in response to innocuous stimuli [68]. However, c-Fos dramatically increases in the dorsal horn following high threshold noxious stimuli $[69,70]$. Increases in c-Fos expression in the superficial dorsal horn also increases through low-intensity innocuous stimulation of regions associated with nerve injury or inflammation [71, 72]. 
Both disinhibition and GluN2B-NMDAR mediated excitation are essential for lamina I hyperexcitation - one mechanism alone cannot produce pain hypersensitivity. In 2016, Hildebrand et al found that these two mechanisms are in fact linked [56]. However, the molecular linker was unknown.

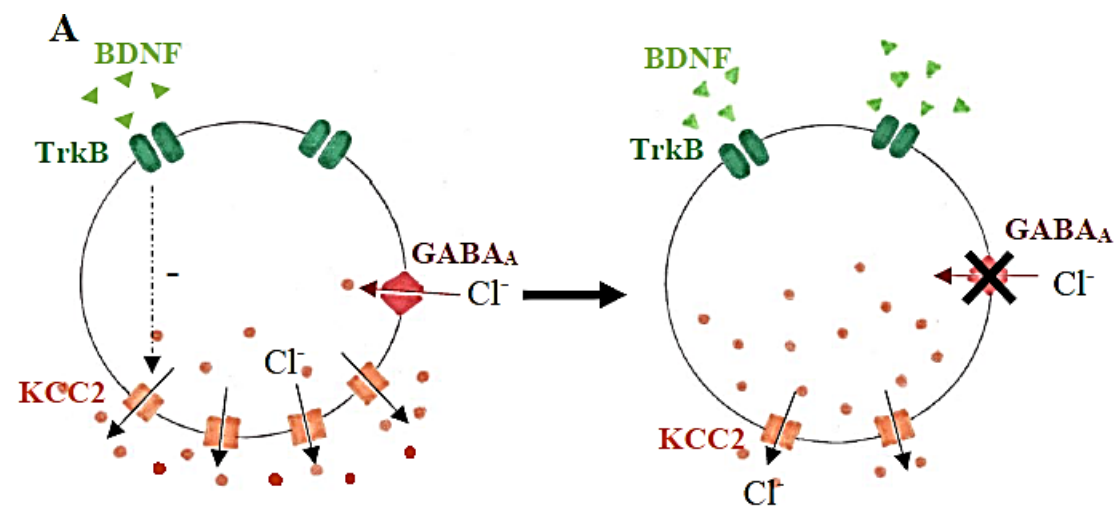

Disinhibition (A)

\section{B. After disinhibition}

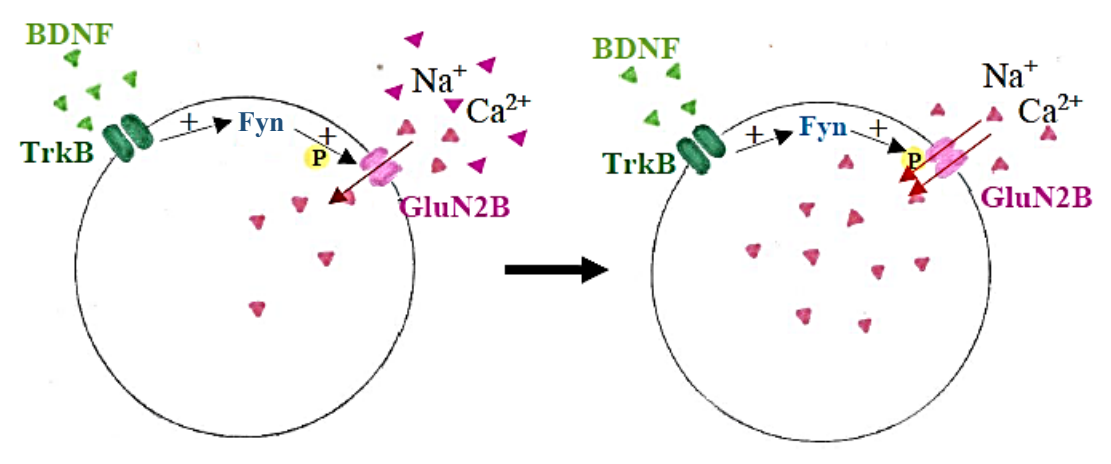

Superficial dorsal horn hyperexcitation

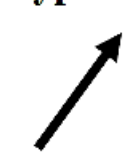

Facilitated excitation (B)

\section{Figure 1. The two mechanisms of BDNF induced superficial dorsal horn neuronal} hyperexcitation in chronic pain. GABAergic inhibition on superficial dorsal horn neurons is lost due to $\mathrm{BDNF}$ downregulating $\mathrm{KCC} 2$ and increasing intracellular chloride ion concentration (Adisinhibition). Following disinhibition, BDNF increases levels of active Fyn kinase which then phosphorylates and potentiates GluN2B-NMDA receptors (B - facilitated excitation). Both mechanisms require BDNF binding to TrkB receptors. 
1.8 STEP 61 - the linker between disinhibition and increased excitation of superficial dorsal horn $\underline{\text { neurons }}$

Membrane associated striatal-enriched tyrosine phosphatase $61\left(\mathrm{STEP}_{61}\right)$ is known for its role in synaptic plasticity [73]. Dysregulation of $\mathrm{STEP}_{61}$ is implicated in many neurodegenerative diseases including Alzheimer's disease, schizophrenia and Parkinson's disease [74-76]. STEP 61 inhibits synaptic strengthening by dephosphorylating other signalling molecules. In fact, $\mathrm{STEP}_{61}$ dephosphorylates GluN2B-NMDARs as well as Fyn kinase in the brain to decrease the activity of these targets [77-80]. In the brain, BDNF degrades $\mathrm{STEP}_{61}$ to modulate its activity [81]. Reduction of STEP 61 increases active Fyn and phosphorylation of GluN2B [79, 80]. Inflammation-induced hyperalgesia leads to decrease in $\mathrm{STEP}_{61}$ activity (by both phosphorylation at serine 221 residue and cleavage) with concurrent increases in phosphorylated GluN2B in the spinal cord [82, 83]. In 2019, we showed that $\mathrm{STEP}_{61}$ is significantly reduced at the superficial dorsal horn in a persistent inflammatory pain model and an ex vivo BDNF model of pathological pain processing [84]. Further, we showed that $\mathrm{STEP}_{61}$ downregulation is required for GluN2B-NMDAR potentiation at lamina I synapses and that blocking KCC2-mediated disinhibition prevents downregulation of STEP $_{61}$. Based on our results we concluded that BDNF-induced disinhibition is linked to GluN2B potentiation in lamina $\mathrm{I}$ synapses via loss of $\mathrm{STEP}_{61}$ in rodent models neuropathic and inflammatory pain.

\subsection{Translational gap in chronic pain between rodent and clinical experiments}

In order to develop more effective chronic pain treatments, identifying the specific biological mechanisms and molecular targets underlying chronic pain is crucial. However, most pain research is done in rodents and almost nothing is known about the spinal mechanisms in 
humans [85]. Thus, there is a vast translational divide between basic research and clinical trials where therapeutic strategies that work in rodents are assumed to be acting on conserved pathological mechanisms in human chronic pain states. However, development of effective therapeutics requires the knowledge of whether spinal mechanisms of pain are conserved between rodents and humans prior to making the aforementioned translational jump. Identifying which elements of spinal pain pathology are conserved and which pathways diverge will enable an evidence-based selection of molecular targets that are validated in humans. However, a significant obstacle to conducting studies using human post-mortem tissue is the limited ability to obtain viable tissue. The long duration between death to tissue collection compromises tissue viability leading to the degradation of required molecules.

\subsection{GluN2B-NMDARs may contribute to superficial dorsal horn hyperexcitability in humans}

Currently, there are only very few studies present in the literature regarding the specific sequence of spinal events in human chronic pain. A study performed by Del Valle et al showed an increased activation of astrocytes and microglia in the spinal cord in a chronic pain patient [86]. Another study reported similar results denoting increased activation of astrocytes in the superficial dorsal horn of pain positive HIV patients [87]. This study also indicated an increased c-Fos expression in the superficial dorsal horn in HIV induced chronic pain. In addition to the above findings, human induced-pluripotent stem cells (ipSCs) that can differentiate into functional neurons were shown to be useful to study the functional properties of NMDARs [88, 89]. Based on these studies, several researchers used human iPSC-derived neurons to show that GluN2B subunit containing NMDAR are dominant and tyrosine phosphorylation of GluN2B by Fyn potentiates NMDAR currents in human iPSCs [90]. 


\subsection{The ex vivo BDNF pathological pain model}

Exogenous BDNF administration to rodents produces similar results as endogenous BDNF in initiating mechanisms of chronic pain. Coull and colleagues showed that intrathecal administration of BDNF progressively increases pain hypersensitivity in rodents [91]. The same study demonstrated that incubation of spinal slices from naïve rats in BDNF results in a significant increase in excitation of lamina I neurons. In addition, the Hildebrand lab has found that ex vivo BDNF results in significantly increased levels of activated Fyn and phosphorylated GluN2B with markedly reduced $\mathrm{KCC} 2$ expression in the rat superficial dorsal horn [56]. These results were consistent with their electrophysiological experiments showing that BDNF pre-treatment leads to downstream Fyn mediated GluN2B phosphorylation and potentiation of NMDAR synaptic responses. In addition, blocking these molecular players seen in the ex vivo BDNF model - BDNF, KCC2 downregulation, disinhibition, Fyn activation, Fyn and Tyr1472 interactions and GluN2B activity - in in vivo rodent nerve injury reverses pain hypersensitivity [36, 62, 91-97]. Although all the above evidence is obtained from rodent models, these studies support that the ex vivo BDNF model of pathological pain is a valid model to test BDNF-induced molecular changes in the human spinal cord.

\subsection{Goals of the current proposal}

1. The first goal of the current proposal was to establish a human ex vivo BDNF-treatment model of chronic pain that parallels previous rodent chronic pain experiments. We collected human spinal cord tissue from organ donors as the surgical procedure for organ donations maintain high viability of the tissue which is critical for the preservation of cellular and molecular expression. We hypothesized that the same coupling between disinhibition and NMDAR potentiation in the 
superficial dorsal horn seen in rodents is conserved in human spinal cord tissue as well. Identifying whether these pathological mechanisms are conserved between species is critical for the translation of chronic pain research from basic science to humans.

2. We used western blotting approaches on isolated superficial dorsal horn synapses to probe changes in synaptic signalling induced by the human ex vivo BDNF model of pathological pain. We investigated the activity of the key elements of the disinhibition-increased excitation pathological pathway of chronic pain, including $\mathrm{KCC} 2$, total and active $\mathrm{STEP}_{61}$, active Fyn and total and phosphorylated GluN2B (pGluN2B) using specific antibodies. Specifically, we tested whether: (A) the pathway is conserved between species (B) the pathway converges or diverges between sexes. Based on what is reported in male rodent chronic pain studies, we hypothesized that ex vivo $\mathrm{BDNF}$ treatment will result in reductions in $\mathrm{KCC} 2$ and active $\mathrm{STEP}_{61}$ and increases in active Fyn and pGluN2B at superficial dorsal horn synapses in male humans. If the hypothesis is supported, we can then conclude that the BDNF-mediated STEP ${ }_{61}$-Fyn-GluN2B pain pathway is conserved in male humans and rodents. For the human female western blots, we hypothesized that the BDNF pain pathway may be potentially different from the males based on evidence in the literature showing differences in spinal pain mechanisms between male and female rodents.

3. The current evidence available on BDNF-induced spinal pathways in chronic pain is limited to functional evidence from electrophysiological recordings on single neurons or western blot analysis on whole superficial dorsal horn tissue. Hence, there is a lack of information regarding where exactly in the spinal cord the effects of BDNF occur. Therefore, we developed a c-Fos staining assay to test: (A) potential changes in spinal cord excitability in the human ex vivo BDNF model (B) whether the effects of BDNF is limited to laminae $\mathrm{I} / \mathrm{II}$ or have a global effect 
throughout the spinal cord, and (C) whether any changes found in excitability is conserved between sexes. We hypothesized that BDNF may increase superficial dorsal horn excitation.

\section{Experimental procedure}

\subsection{Human spinal cord isolation}

Spinal cord tissue from male and female organ donors (18-70 years old) was obtained through the Trillium Gift of Life network. The approval of the Ottawa Health Science Network Research Ethics Board was obtained prior to human tissue collection and experiments with human tissue. Approximately $50 \%$ of the donors died from brain hemorrhage, $15 \%$ from traumatic brain injury, $10 \%$ from cerebral aneurysm, $10 \%$ from subdural hematoma, $5 \%$ from cerebral thrombosis, $5 \%$ from hypoxic asphyxiation and 5\% from coronary artery disease and hypertension. Before organ removal, the body was cooled down to hypothermic conditions and perfused with high magnesium protective solution (Celsior/Belzer UW cold solution). After the removal of organs for donation, the spinal cord was dissected out using ventral laminectomy within $119 \pm 24$ minutes $(n=25)$ following cross clamping of the heart. Once the spinal cord is removed from the body, the lumbar and thoracic regions were placed in ice cold and bubbled (with 95\% oxygen and 5\% carbon dioxide) aCSF in order to maintain tissue viability in the duration taken to transport the tissue to the laboratory for required experiments.

Human tissue for western blotting and immunohistochemistry was treated according to the ex vivo BDNF model described below. Following treatment, the samples for western blotting were flash frozen using liquid nitrogen and stored in $-80^{\circ} \mathrm{C}$. The samples for immunohistochemistry were fixed with $4 \%$ paraformaldehyde. 


\subsection{Human ex vivo BDNF model of pathological pain}

Following the extraction of the spinal cords as previously described, the tissue was placed in $\mathrm{aCSF}$ at room temperature containing $100 \mathrm{ng} / \mathrm{mL}$ (human) recombinant BDNF (Alomone Labs) or aCSF alone for 70-80 minutes while continuously bubbling the solutions with $95 \%$ oxygen and $5 \%$ carbon dioxide.

\subsection{Isolation of synaptic fractions and biochemical analysis of human spinal tissue}

The human lumbar and thoracic spinal cord sections that were treated according to the ex vivo $\mathrm{BDNF}$ model and stored in $-80^{\circ} \mathrm{C}$ were separated into the superficial dorsal horn and the rest of the spinal cord (i.e. deeper dorsal horn and ventral horn). For this, approximately $4 \mathrm{~mm}$ of the superficial dorsal horn was separated from the rest of the cord on dry ice using a scalpel blade.

To obtain total homogenates, the tissue was homogenized using Wheaton Dounce Tissue Grinders (10-15 times using the loose fitting pestle followed by 10-15 times using the tight fitting pestle) in $300 \mu \mathrm{l}$ of ice cold TEVP-320mM sucrose buffer (1mM Tris- $\mathrm{HCl} \mathrm{pH} 7.4,5 \mathrm{mM} \mathrm{NaF}$, 1mM Na3VO4, 1mM EDTA, 1mM EGTA and 320mM sucrose) containing Roche complete

protease inhibitor. A portion of the homogenates was centrifuged at $1000 \mathrm{xg}$ for 10 minutes at $4^{\circ} \mathrm{C}$. The supernatant was further centrifuged at $12,000 \times \mathrm{g}$ for 15 minutes at $4^{\circ} \mathrm{C}$ to obtain the crude synaptosomal fraction. The pellet was resuspended in TEVP-320mM sucrose buffer by brief sonication.

The protein concentration of the homogenates and the synaptosomes was determined by Pierce BCA protein assay kit. $30 \mu \mathrm{g}$ of protein from each sample was loaded onto $8 \%$ SDS-PAGE and transferred to PVDF membranes (Bio-Rad). 
Membranes were first incubated in blocker solution containing 5\% BSA in TBS $+0.1 \%$ TWEEN-20 (TBST) and then in primary antibodies (anti-STEP [1:1000], anti-KCC2 [1:1000], anti-Fyn [1:1000] and anti- $\beta$-actin [1:10000] from Santa Cruz; anti-non-phospho-STEP [1:1000] from Cell Signalling; anti-pY1472GluN2B [1:1000] and anti-pY1325GluN2A [1:1000] from PhosphoSolutions; anti-GluN2B [1:2000] and anti-GluN2A [1:1000] from Millipore) overnight in 5\% BSA + TBST. Following 3 TBST washes, the membranes were incubated in horseradish peroxidase (HRP) - conjugated anti-mouse or anti-rabbit secondary antibodies [Pierce; 1:5000] for 2 hours at room temperature. The membranes were then developed using Pierce chemiluminescent substrate kit and visualized using G:BOX with the GeneSnap software (Syngene). The signals were quantified using ImageJ (NIH).

\section{4 cFos, cresyl violet, CGRP and $\mathrm{KCC} 2$ immunostaining}

$\underline{\text { cFos and cresyl violet immunostaining }}$

Following BDNF/aCSF treatment, the cord sections were incubated in $4 \% \mathrm{PFA}$ in $0.1 \mathrm{M}$ Phosphate Buffer (PB, $\mathrm{pH} 7.2)$ for approximately 36 hours. The cords were then incubated in $10 \%$ sucrose in PB overnight followed by another two-hour incubation in fresh $10 \%$ sucrose. The cords were then transferred into 30\% sucrose in PB for a minimum of 48 hours. All incubations were done at $4^{\circ} \mathrm{C} .25 \mu \mathrm{m}$ thick transverse spinal cord sections were obtained using a Leica $3050 \mathrm{~S}$ cryostat. The sections were washed $3 \times 5$ minutes in $0.01 \mathrm{M}$ Phosphate Buffered Saline (PBS; pH 7.4) with $0.1 \%$ Triton $X$ (PBS-Tx). The sections were then incubated in $0.3 \%$ hydrogen peroxide in PBS-Tx for 30 minutes followed by another 3 x 5 minutes PBS-Tx washes. Then tissue was incubated in blocker solution $(500 \mu 1$ normal goat serum - Sigma, $300 \mu 110 \%$ Triton-X and $9.2 \mathrm{ml}$ PBS) for 30 minutes. The sections were then incubated in polyclonal rabbit primary anti-c-Fos 
antibody (Cedarlane; 1:5000) in 500 $\mu 1$ normal goat serum, $300 \mu 110 \%$ Triton-X, $1.5 \mathrm{ml} 2 \%$ BSA and $7.7 \mathrm{ml}$ PBS overnight at room temperature.

The sections were washed $3 \times 5$ minutes in PBS-Tx and incubated in blocker solution containing secondary biotinylated anti-rabbit secondary antibody (1:500; Jacksonimmuno Labs) for 2 hours at room temperature. The sections were washed $3 \times 5$ minutes in PBS-Tx. The sections were then incubated in $\mathrm{ABC}$ peroxidase solution (Thermoscientific; Reagent $\mathrm{A}-1.5 \%$, Reagent B - 1.5\%) in PBS-Tx for one hour. Following 3 X 5 washes of PBS only, a DAB (Sigma-Aldrich; 3,3 diaminobenzidine) reaction was performed. $12.5 \mathrm{mg} \mathrm{DAB} / 25 \mathrm{ml}$ PBS solution was prepared. $625 \mu 1$ of $1 \%$ Cobalt chloride in distilled water (Fisher Scientific) and $500 \mu 1$ of $1 \%$ Nickel ammonium sulfate in distilled water (Fisher Scientific) were added to the DAB solution. Just prior to adding the solution to the spinal sections, $25 \mu$ l of $30 \%$ hydrogen peroxide was added to the DAB solution. The sections were developed for 5 minutes in the DAB solution. The sections were then washed 3 x 5 minutes with PBS and mounted on Superfrost Plus positively charged slides (Fisherbrand) and allowed to air dry overnight.

Next, the sections were dehydrated with $70 \%$ ethanol for 2 minutes followed by another 2 minute wash with $90 \%$ ethanol. Then the sections were dehydrated using $100 \%$ ethanol 2 × 3 minutes and an additional 5 minutes in fresh $100 \%$ ethanol. The sections were cleared using clearene $2 \times 3$ minutes and an additional 5 minutes with fresh clearene. The slides were coverslipped using DPX mounting medium.

During the dehydration process, a subset of tissue sections were also stained with Cresyl violet stain to label neuronal nuclei. The modified dehydration process for cresyl violet stain consisted of $70 \%$ ethanol wash ( 2 minutes), $95 \%$ ethanol wash (2 minutes), $100 \%$ ethanol wash ( $2 \times 2$ minutes) followed by $100 \%$ ethanol wash ( $2 \times 2$ minutes), $95 \%$ ethanol wash ( 2 minutes), $70 \%$ 
ethanol wash and distilled water washes ( $3 \times 2$ minutes). This was followed by a $1 \%$ cresyl violet wash ( 3 minutes), distilled water washes ( $3 \times 2$ minutes), acetic acid wash ( $4 \mathrm{mls}$ glacial acetic acid in 500mls of distilled water; 3 minutes) and distilled water washes (3x2 minutes). Next, a $70 \%$ ethanol wash ( 2 minutes), 90\% ethanol wash ( 2 minutes) and $100 \%$ ethanol washes ( $2 \times 2$ minutes) were done. Finally, the sections were washed in clearene ( $3 \times 3$ minutes) and coverslipped using DPX.

\section{CGRP immunostaining}

Unmyelinated c-fibers that release calcitonin gene-related peptide (CGRP) terminate specifically at lamina I and outer lamina II (IIo) region [98]. Therefore, CGRP stain was used to label the superficial dorsal horn. A mouse monoclonal anti-CGRP primary antibody (Sigma; 1:5000) and a secondary biotinylated anti-mouse secondary antibody (Jacksonimmuno labs; 1:500) were used. The staining procedure for CGRP was the same as the human c-Fos immunostaining protocol. The CGRP-stained region was used to outline the superficial dorsal horn region during c-Fos quantification.

\section{Quantification of c-Fos expression}

Stereo Investigator 2018 program was used to take images of the superficial dorsal horn of the spinal slices at 20x magnification. Image-J program was used for c-Fos quantification. The outline of the superficial dorsal horn was obtained for each subject based on CGRP staining. The outline was then superimposed on c-Fos stained tissue sections. Following this, c-Fos positive cells within the superficial dorsal horn were counted manually using the multi-point tool on Image-J. cFos expression in six spinal cord slices was quantified per individual per treatment. 


\section{$\underline{\text { KCC2 immunostaining }}$}

Following ex vivo BDNF or saline treatment, cord sections were transferred to antifreeze solution $(28.7 \mathrm{ml}$ of $27.6 \mathrm{~g} / \mathrm{L}$ sodium phosphate monobasic $(\mathrm{pH} 7.3), 96.3 \mathrm{ml}$ of $28.4 \mathrm{~g} / \mathrm{L}$ sodium phosphate dibasic ( $\mathrm{pH} 7.3$ ), 375ml of $100 \mu \mathrm{l} / \mathrm{L}$ diethylpyrocarbonate water, 300ml Ethylene glycol, $200 \mathrm{ml}$ glycerol) until sectioning to prevent freeze-thaw of tissue stored at $-20^{\circ} \mathrm{C}$.

Transverse cord sections of $25 \mu \mathrm{m}$ thickness were cut using a Leica SM2000R microtome. The tissue sections were washed in PBS ( $\mathrm{pH} 7.4$ ) containing $0.2 \%$ Triton-X (PBST) for 10 minutes followed by two more washes in PBS only. Cord sections were then incubated in rabbit polyclonal primary anti-KCC2 antibody (1:1000, Millipore) and mouse monoclonal primary anti-CGRP antibody (1:5000, Sigma) for 12 hours at $4^{\circ} \mathrm{C}$ in $10 \%$ normal goat serum in PBST. Tissue sections were washed in PBS and incubated in goat-Cy3 anti-rabbit purified secondary antibody (1:500, ThermoFisher), goat anti-mouse Alexa Fluor 647 secondary antibody (1:500, ThermoFisher) and DAPI (1:500, ThermoFisher) in 10\% normal goat serum in PBST for 2 hours at room temperature. The sections were mounted on SuperFrost gelatin-subbed slides (Fisherbrand) and coverslipped using florescence mounting medium.

\section{Quantification of KCC2 expression}

Confocal images were taken using a Zeiss LSM 880 confocal laser scanning microscope set to 12 -bit resolution with 2048 x 2048 pixel size and $10 \mu$ s pixel dwell time. The images were taken at 63x for high magnification. Quantification and changes in KCC2 intensity was detected using MATLAB routines as previously described [84]. In brief, CGRP was used as a marker of the superficial dorsal horn and only the neurons the CGRP expressing region was quantified. The experimenter was blind to the treatment conditions of the samples. 118 neurons for saline and 108 
neurons for BDNF were analyzed for $n=9$ males. The analyzed neurons were grouped into two groups: neurons that expressed strong membrane KCC2 staining (i.e KCC2 expression at $0 \mu \mathrm{m}$ distance from neuron membrane) and neurons expressing strong intracellular KCC2 staining (KCC2 expression between $0.5 \mu \mathrm{m}$ and $2.5 \mu \mathrm{m}$ from the neuronal membrane).

\section{$\underline{2.5 \text { Statistical analysis }}$}

All data is presented as mean \pm standard error of the mean. As all targets were compared between saline versus BDNF-treated spinal cord sections that came from the same individual $(n=23)$, the means were compared using paired student's t test (Microsoft Excel Office 365) for western blots as well as cFos expression. To test statistical significance of sex differences in western blots, unpaired t-test (unequal variance) was used. 2-way parametric paired t-tests were done to test the significance of KCC2 intensity at the membrane and in the intracellular compartment. For cFos staining, density measurements were used to calculate sex*treatment interaction and 2-way ANOVA was used to test the statistical significance between sexes. $\mathrm{p}<0.05$ was considered statistically significant.

\section{Results}

The current knowledge regarding spinal mechanisms of pathological pain processing in humans is limited due to a lack of studies performed on human spinal cord tissue. In order to compare whether rodent spinal pain mechanisms are conserved in humans, we therefore established an ex vivo BDNF model of pain processing using human spinal cord tissue collected from 18 to 70 years old male and female neurological determination of death organ donors (Figure 2). In this model, adjacent spinal cord sections were pretreated with $100 \mathrm{ng} / \mathrm{ml}$ recombinant BDNF or saline for 70 minutes. We collected lumbar, thoracic and sacral regions of 
the spinal cord within 1-3 hours $(119 \pm 24$ minutes, $\mathrm{n}=25)$ following aortic cross clamping to preserve high neuronal viability in the spinal sections. In fact, the human spinal tissue was so viable that we were able to perform patch clamp recordings on a subset of human lamina I neurons (Dedek et al, Brain, 2019).This study excluded spinal tissue from patients with chronic pain, infectious diseases and medical conditions or medications affecting spinal pain processing.

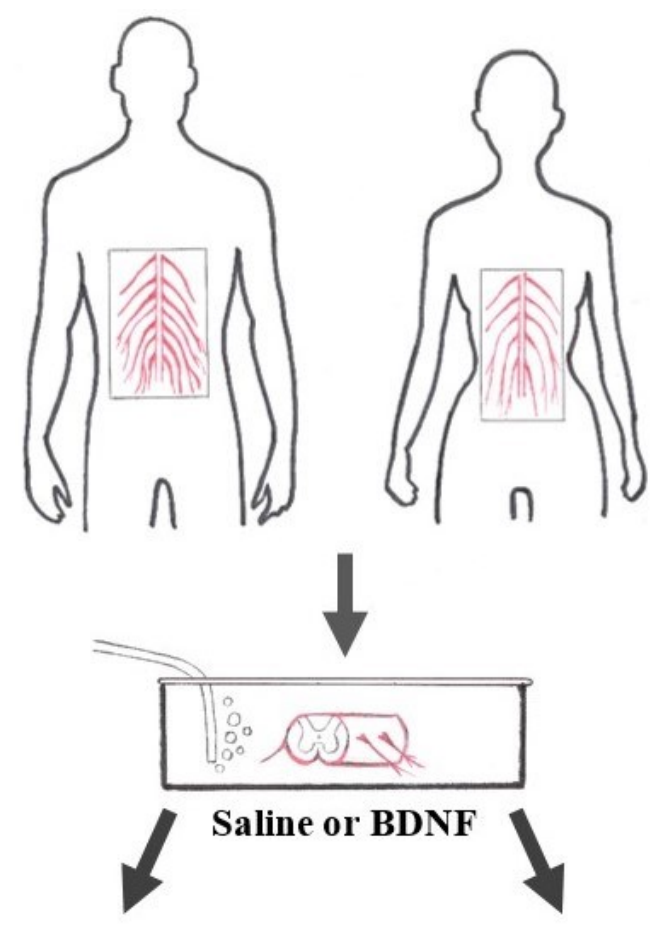

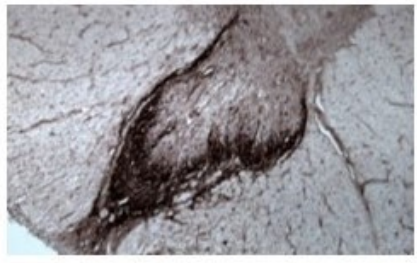

Immunohistochemistry

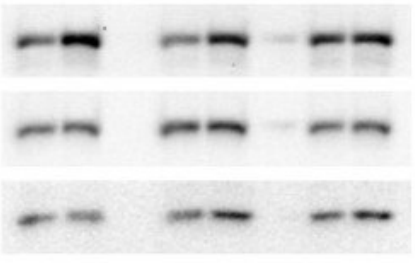

Western Blotting

Figure 2: The human ex vivo BDNF model. Highly viable thoracic, lumbar or sacral regions of male and female human spinal cords were incubated in $100 \mathrm{ng} / \mathrm{mL}$ recombinant BDNF or saline for 70 minutes before performing immunohistochemistry (thoracic, lumbar or sacral region) and western blotting (thoracic or lumbar region). 


\begin{tabular}{|c|c|c|c|}
\hline Patient ID & Sex & Age & $\begin{array}{c}\text { Experiments performed on spinal } \\
\text { tissue samples }\end{array}$ \\
\hline P3 & M & 56 & Western blotting \\
\hline P4 & $\mathrm{M}$ & 42 & Western blotting \\
\hline P5 & $\mathrm{F}$ & 66 & Western blotting \\
\hline P6 & $\mathrm{M}$ & 53 & Western blotting \\
\hline P7 & F & 36 & cFos staining \\
\hline P9 & $\mathrm{M}$ & 69 & Western blotting \\
\hline P10 & $\mathrm{F}$ & 69 & Western blotting, cFos staining \\
\hline P11 & $\mathrm{M}$ & 33 & Western blotting, KCC2 staining, cFos staining \\
\hline P12 & $\mathrm{M}$ & 66 & Western blotting \\
\hline P13 & $\mathrm{M}$ & 63 & Western blotting, KCC2 staining, cFos staining \\
\hline P14 & M & 22 & KCC2 staining, cFos staining \\
\hline P16 & M & 52 & Western blotting, KCC2 staining, cFos staining \\
\hline P17 & M & 64 & Western blotting, $\mathrm{KCC} 2$ staining, cFos staining \\
\hline P18 & M & 18 & KCC2 staining, cFos staining \\
\hline P19 & $\mathrm{F}$ & 24 & Western blotting, cFos staining \\
\hline $\mathbf{P 2 0}$ & $\mathrm{F}$ & 67 & Western blotting \\
\hline P21 & $\mathrm{F}$ & 27 & cFos staining \\
\hline P22 & M & 58 & KCC2 staining, cFos staining \\
\hline P24 & $\mathrm{F}$ & 68 & Western blotting, cFos staining \\
\hline P25 & $\mathrm{F}$ & 58 & Western blotting, cFos staining \\
\hline P26 & $\mathrm{M}$ & 53 & KCC2 staining \\
\hline P27 & $\mathrm{M}$ & 55 & KCC2 staining \\
\hline P29 & M & 56 & cFos staining \\
\hline
\end{tabular}

Table 1. Demographics of spinal tissue donors and the experiments performed on the tissue samples. 
To compare spinal pain mechanisms in adult human males versus adult male rats, western blots were performed on crude synaptosomal samples of lumbar or thoracic regions of adult human male spinal cords ( $\mathrm{n}=8,30-70$ years of age) following ex vivo BDNF-treatment. As observed in male rats (Dedek et al, Brain, 2019) we found that the same trends were observed in male humans showing significant decreases in $\mathrm{KCC} 2(\mathrm{p}=0.044)$ by $25 \%$, total $\mathrm{STEP}_{61}(\mathrm{p}=0.019)$ by $18 \%$ and active $\mathrm{STEP}_{61}(\mathrm{p}=0.048)$ by $18 \%$ and significant increases in active Fyn $(\mathrm{p}=0.04)$ by $35 \%$ and pGluN2B $(\mathrm{p}=0.031)$ by $43 \%$ at the superficial dorsal horn of BDNF incubated tissue compared to saline treatment (Figure 3). We did not see effects of BDNF on total GluN2A or phosphorylated GluN2A. These molecular changes were not observed in the remainder of the spinal cord or total cell homogenates.

Next, we compared if the changes in the BDNF pathway seen in male rats and humans are similar or different in female human spinal cord tissue. We performed western blots on the crude synaptosomal fractions obtained from the superficial dorsal horn in the lumbar region of six adult females (24-69 years old). We found that ex vivo BDNF treatment did not induce any significant changes in $\mathrm{KCC} 2(\mathrm{p}=0.332)$, active $\mathrm{STEP}_{61}(\mathrm{p}=0.874)$, total STEP $(\mathrm{p}=0.773)$, $\mathrm{pFyn}$ $(\mathrm{p}=0.494)$ or $\mathrm{pGluN2B}(\mathrm{p}=0.600)$ in the female spinal tissue compared to saline treatment due to high variance between the samples (Figure 4). Similarly, the differences of these molecules were not significant between the sexes $\left(\mathrm{KCC} 2 \mathrm{p}=0.516\right.$, active $\mathrm{STEP}_{61} \mathrm{p}=0.349$, total $\mathrm{STEP}_{61} \mathrm{p}=0.380$, pFyn $\mathrm{p}=0.650$, pGluN2B $\mathrm{p}=0.654)$.

We also tested the membrane expression of $\mathrm{KCC} 2$ in the superficial dorsal horn neurons using immunohistochemistry in nine adult male (18-64 years old) spinal cords treated according to the ex vivo BDNF model. CGRP immunostaining is specific to the nociceptive peptidergic afferents found only in the superficial dorsal horn. The superficial dorsal horn was labelled using 

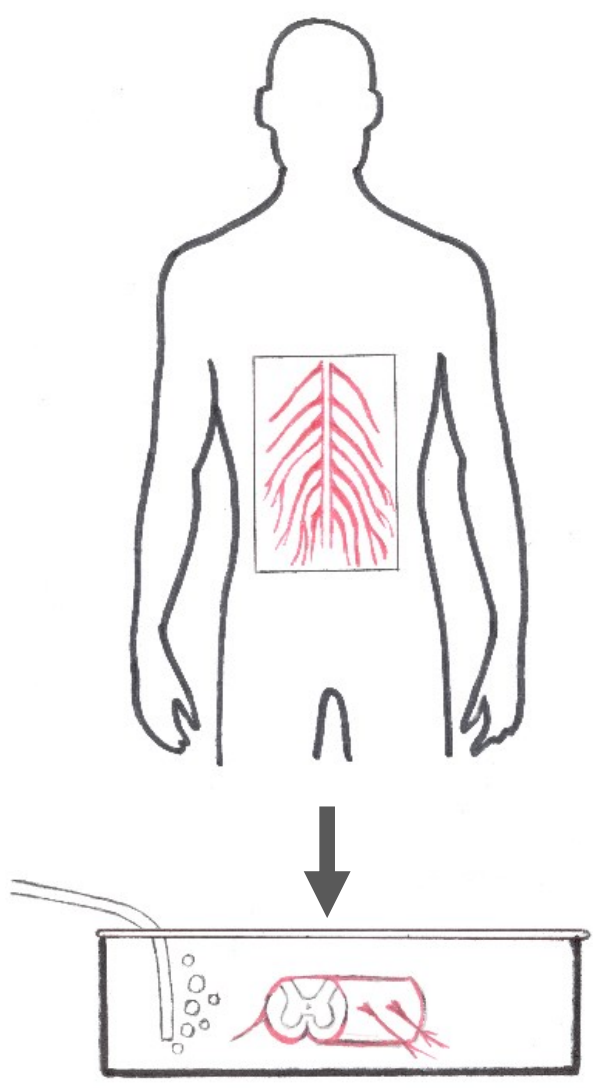

Figure 3: Ex vivo BDNF model of spinal pain processing downregulates $\mathrm{KCC} 2$ and STEP61 and upregulates pFyn and pGluN2B in the superficial dorsal horn synapses of adult male human spinal cord tissue. Plots and representative blots comparing BDNF- ("B", red) versus saline- ("S", white) treated male human (30-70 years old) superficial dorsal horn synaptosomes $(n=9) . \quad \beta$-actin was used as the control to normalize all targets. $*=\mathrm{p}<0.05$
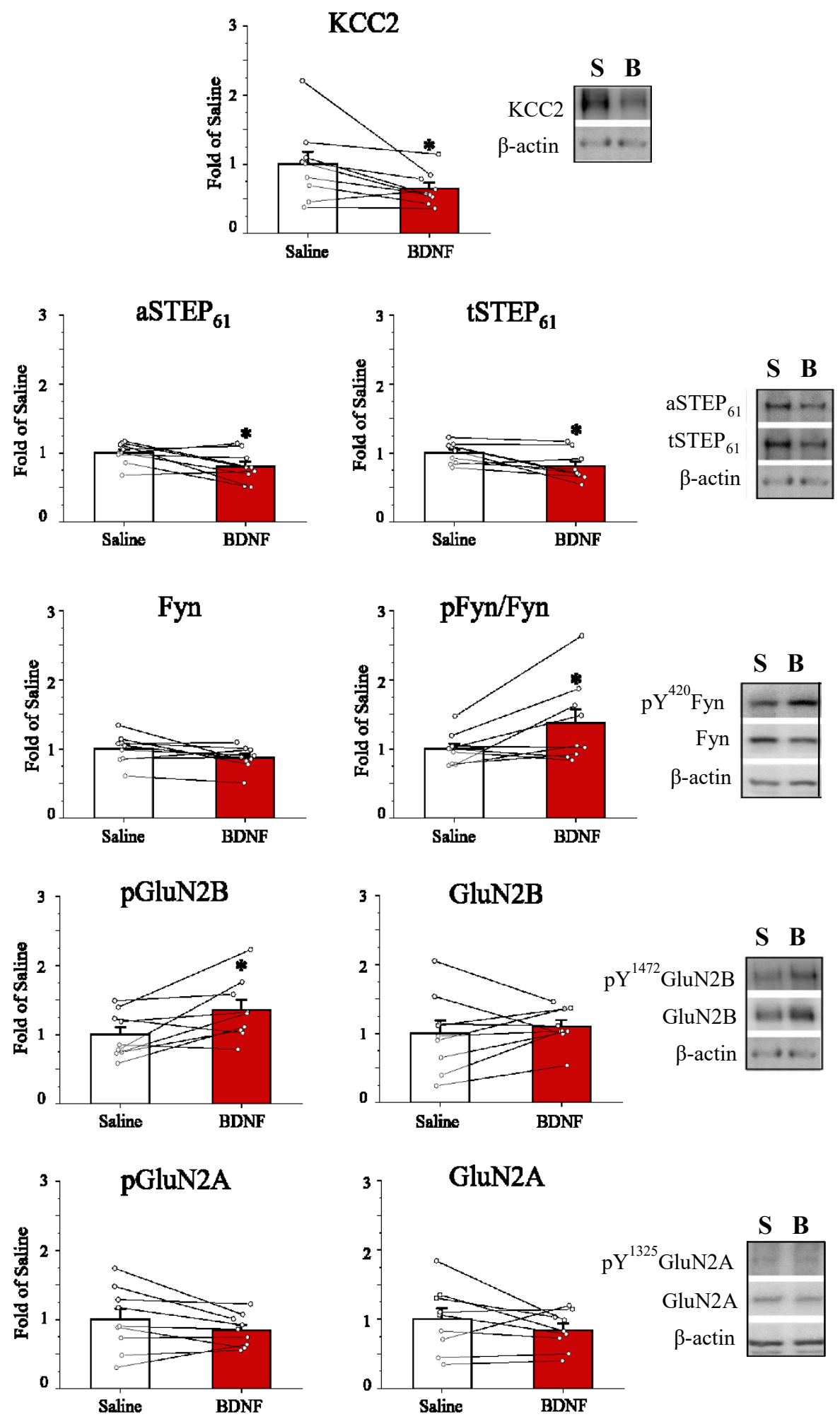


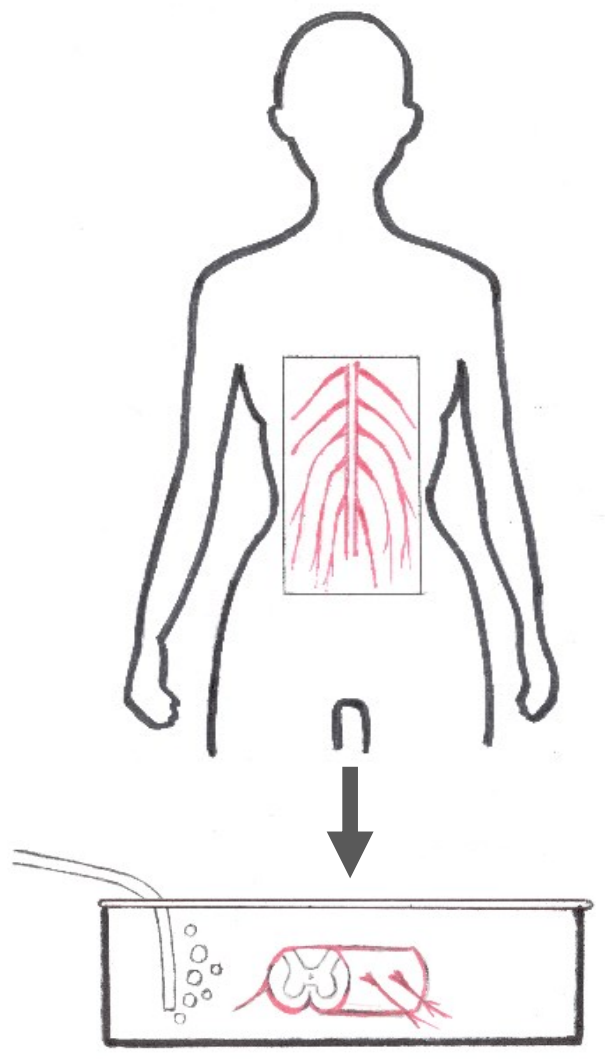

Figure 4: Ex vivo BDNF model of spinal pain processing does not show significant changes in KCC2, STEP61, pFyn and pGluN2B in the superficial dorsal horn synapses of adult female human spinal cord tissue. Plots and representative blots comparing BDNF (red) versus saline (white) treated female human (24-69 years old) superficial dorsal horn $(n=6)$. $\beta$ actin was used as the control to normalize all targets. $*=p<0.05$
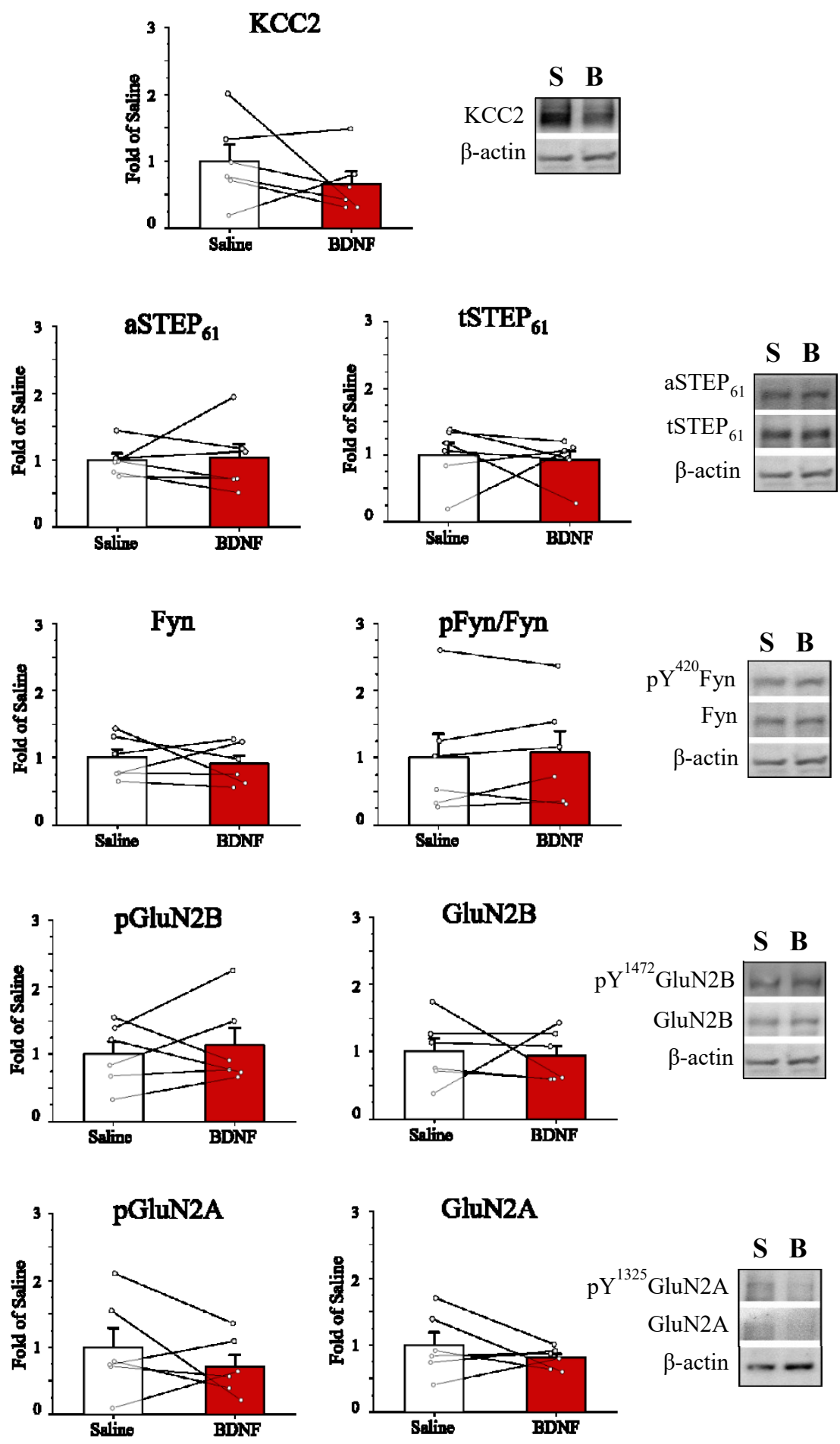
CGRP stain and $\mathrm{KCC} 2$ staining only within that region was quantified (Figure $5 \mathrm{~A}$ and $\mathrm{B}$ ). A significant decrease in KCC2 at neuronal membranes was seen in the BDNF treated superficial dorsal horns compared to the controls (Figure $5 \mathrm{~A}-\mathrm{D}$ ). In addition, a concurrent significant increase in intracellular $\mathrm{KCC} 2$ was seen in $\mathrm{BDNF}$ treated tissue compared to saline controls suggesting that BDNF may induce KCC2 internalization in superficial dorsal horn neurons $\left(\chi^{2}\right.$ test $=61.71)($ Figure $5 \mathrm{E})$. Similar immunostaining results were seen in preliminary experiments adult female superficial dorsal horn neurons treated with BDNF (data not shown).
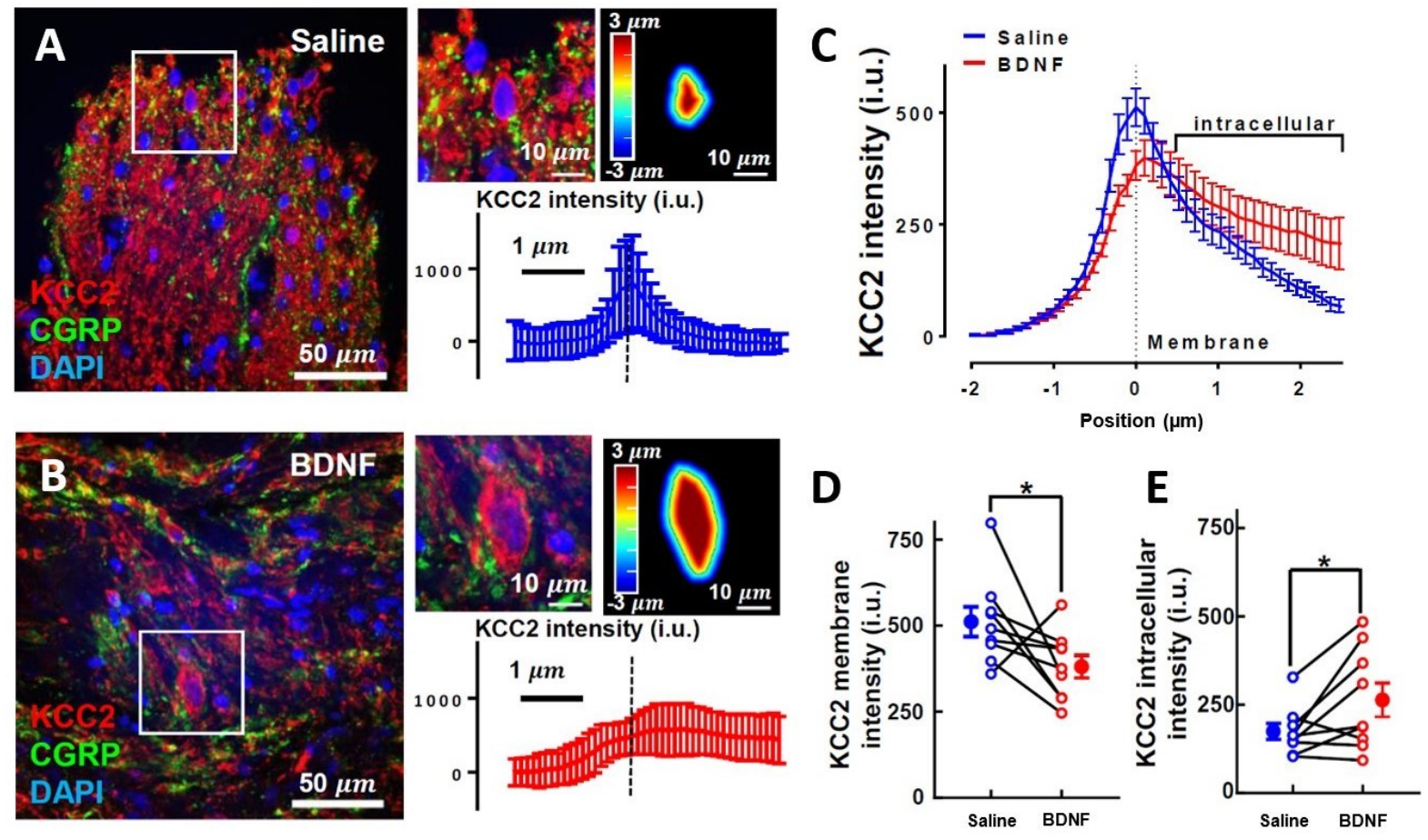

Figure 5: Ex vivo BDNF treatment induced a significant decrease in KCC2 expression at neuronal membranes with an associated increase in intracellular $\mathrm{KCC} 2$ expression in human males. Representative confocal images of spinal cord treated with (A) saline or (B) BDNF; KCC2 (red), CGRP (green) and DAPI (blue). The top middle image in panels A and $\mathrm{B}$ show a zoomed neuron expressing $\mathrm{KCC} 2$. The top right image is a colour-coded distance map showing the spatial value of analyzed pixels relative to the membrane (defined as $0 \mu \mathrm{m}$ ). The bottom plot shows KCC2 intensity versus its distance from the membrane. (C) Average KCC2 expression in the superficial dorsal horn neurons treated with saline (blue) compared with BDNF (red) in 18-64 years old male humans ( $n=9$ ). (D) Average membrane KCC2 levels of superficial dorsal horn spinal cord neurons incubated in saline versus BDNF. (E) Average intracellular KCC2 levels of superficial dorsal horn spinal cord neurons incubated in saline versus BDNF. 
Further, we used cFos immunostaining to identify if changes in synaptic responses produced by BDNF translate to changes in overall excitability of dorsal horn neurons, and if so, where in the dorsal horn this effect is occurring in adult human male and female spinal sections. Again, CGRP stain was used to identify the superficial dorsal horn region of each tissue sample as the morphology of the superficial dorsal horn changes vastly depending on whether the section comes from the thoracic, lumbar or sacral spinal cord (Figure 6).
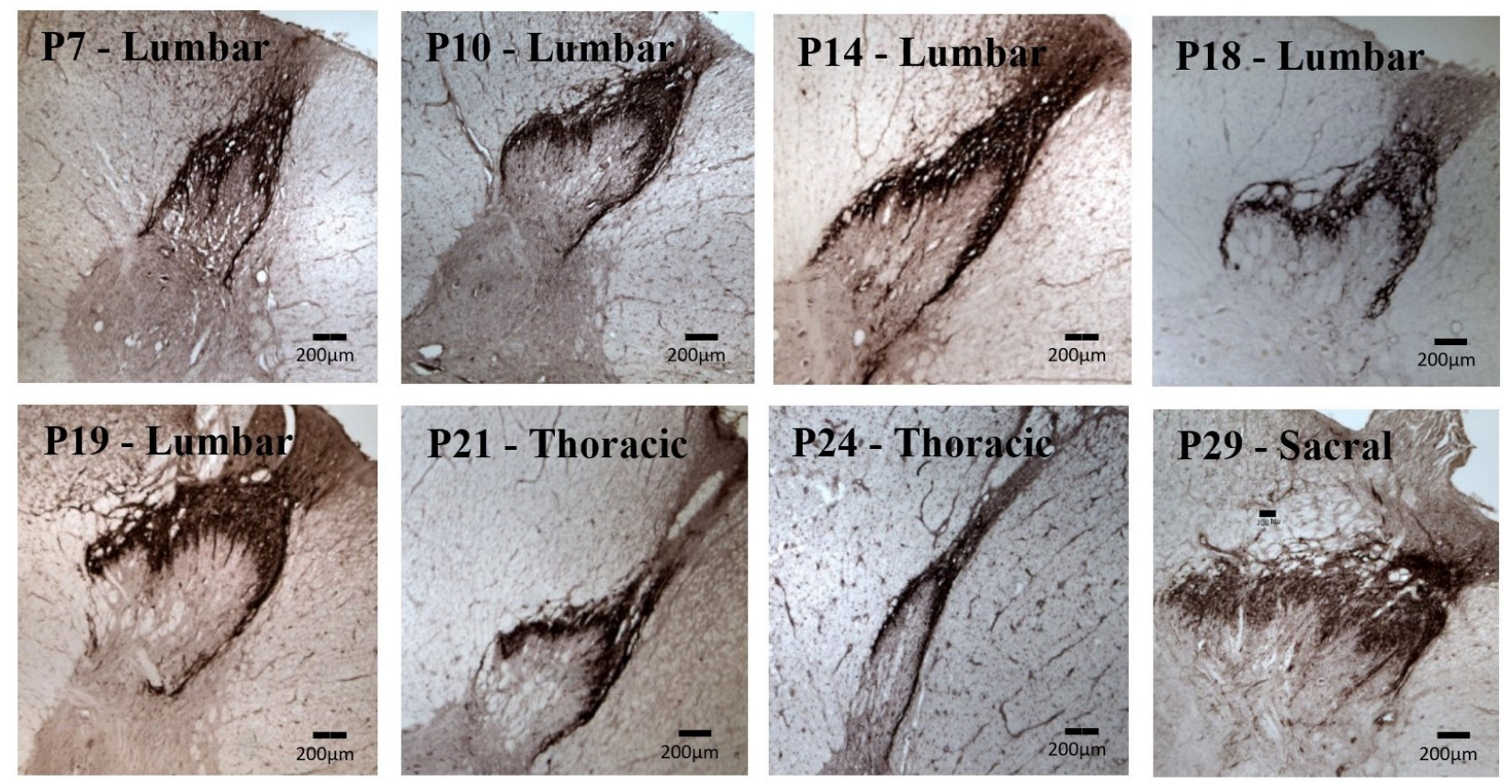

Figure 6: CGRP expression specific to the nociceptive peptidergic afferent terminals in the superficial dorsal horn lamina I and outer lamina II. Representative images of the different morphologies of the superficial dorsal horn depending on the spinal cord region $(2.5 \mathrm{x}$ magnification). A mouse monoclonal anti-CGRP primary antibody was used and a DAB reaction was performed to visualize the CGRP staining.

The appropriate CGRP outline was superimposed on the same patient's cFos-stained tissue sections on ImageJ and the cFos-labelled neurons were quantified manually using the multi-point tool strictly within this superficial dorsal horn region (Figure 7). As cFos is largely expressed in neuronal nuclei, we confirmed that the cFos primary antibody used is specific to 
neuronal nuclei. We used cresyl violet, a marker for neuronal nuclei, to compare the size of nuclei to cFos staining to confirm that the cFos stained nuclei are the same size as the cresyl violet stained nuclei (Figure 8). We also confirmed that the cFos staining detected is not due to any background staining by performing a negative stain without using the primary cFos antibody in the staining protocol (Figure 9).
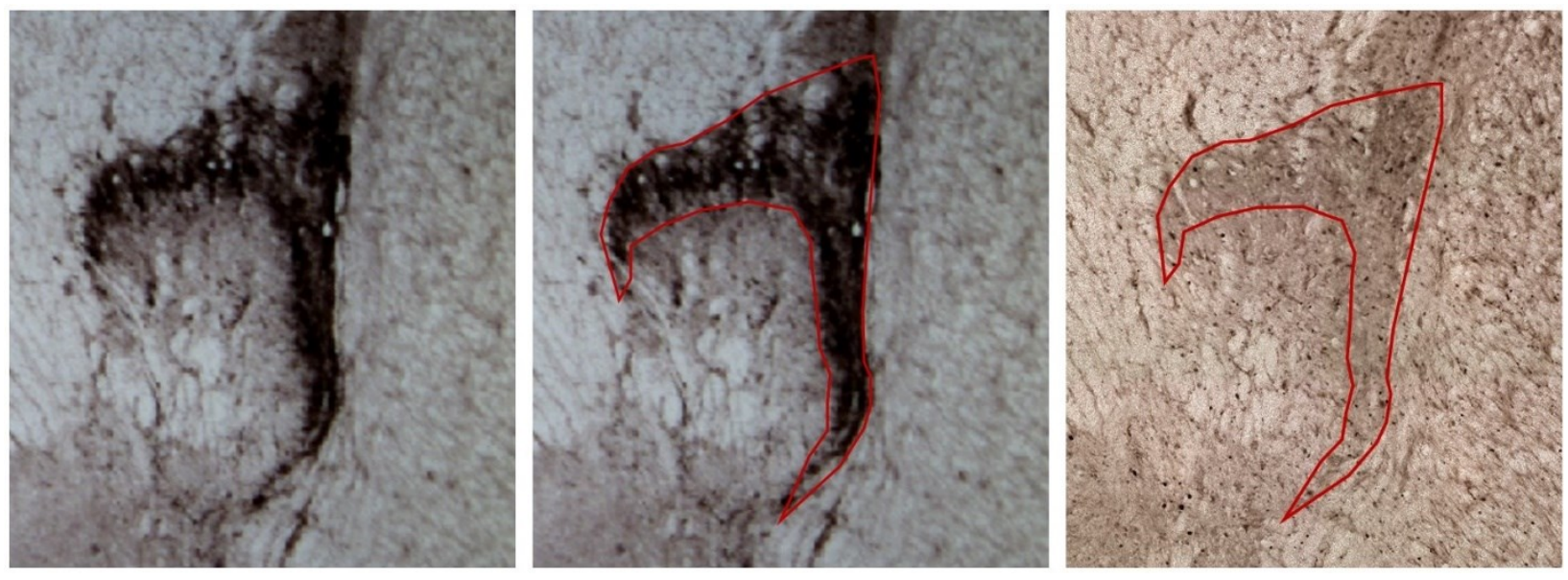

Figure 7: CGRP staining was used to demarcate the superficial dorsal horn region. In each human spinal cord sample on ImageJ program to quantify cFos expression only within the superficial dorsal horn region.

cFos expression in the saline-treated superficial dorsal horns of eight males (Figure $10 \mathrm{~A}$ ) and six females (Figure 10 B) indicated very high individual variability. Our hypothesis was that BDNF treatment would increase neuronal hyperexcitability in the superficial dorsal horn, which would be indicated by an increase in cFos-positive cells. There was a trend showing increased (41.4\% increase) cFos density in BDNF treated male superficial dorsal horn but a decrease $11.96 \%$ decrease) in female BDNF-treated superficial dorsal horn compared to saline treatment (Figure 11). However, 2-way ANOVA did not show a significant sex difference in the density of cFos expression in BDNF versus control treatment. 


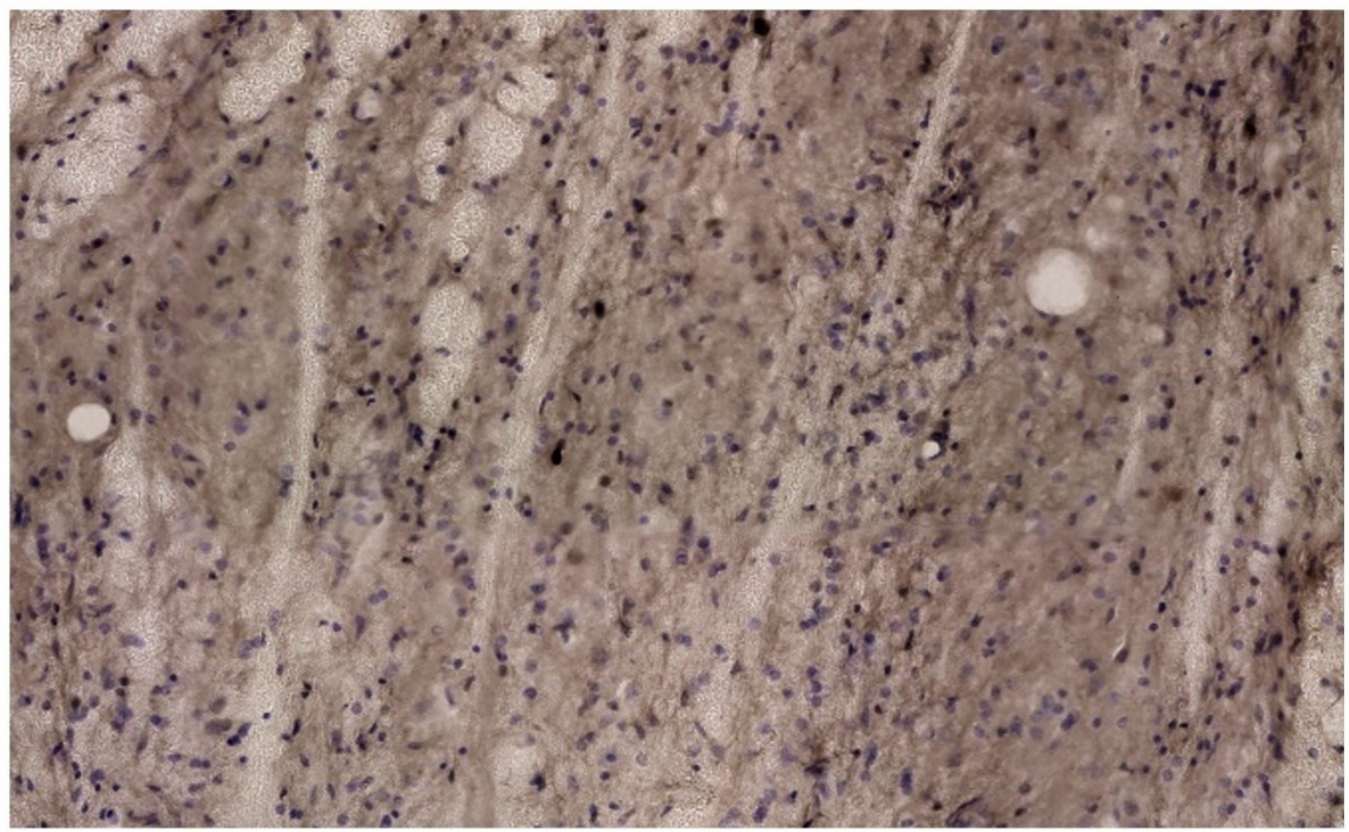

Figure 8: cFos staining patterns match cresyl violet positive cell distribution. Cresyl violet (purple) co-stained with cFos (black) to assess non-specific staining and identify cFos immunolabelling that was specific to neuronal nuclei.

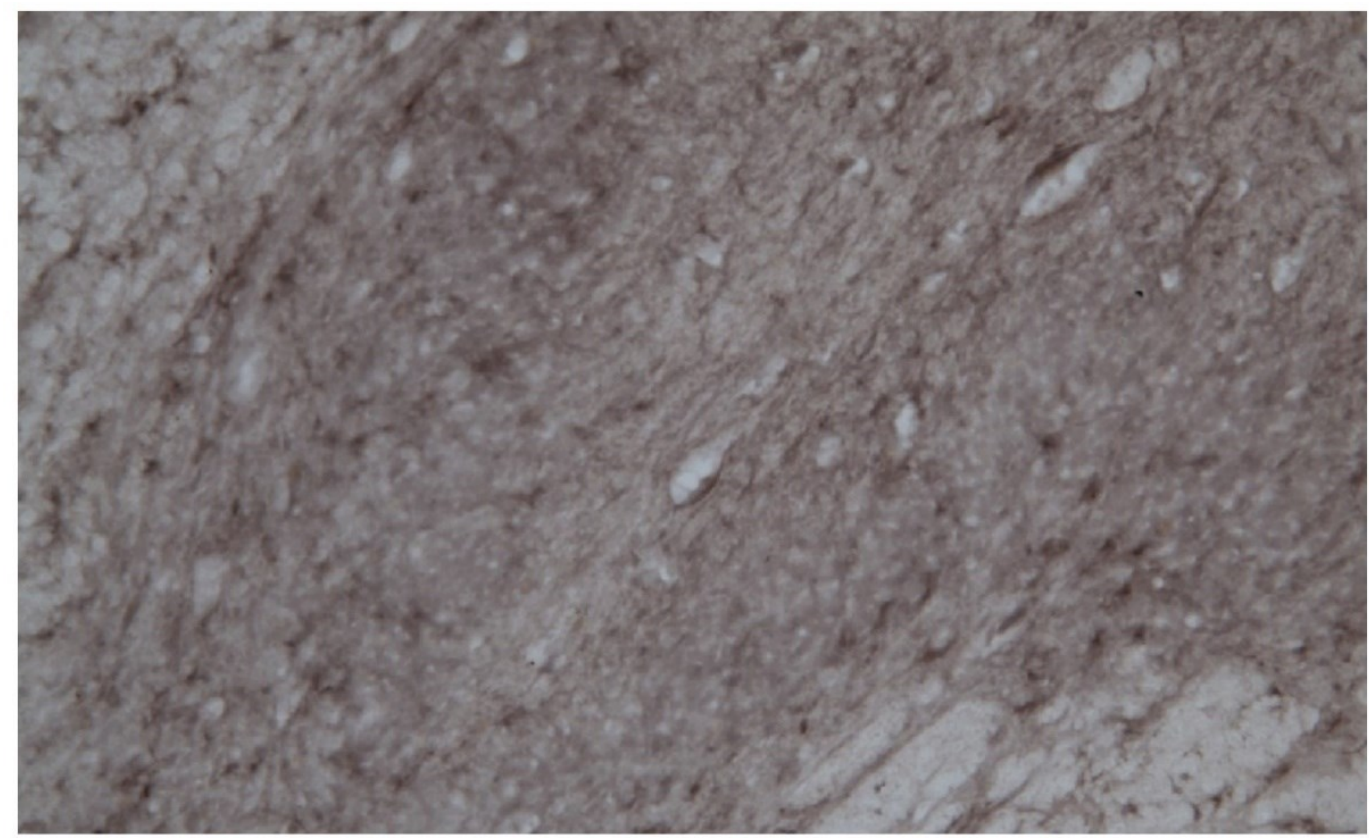

Figure 9: cFos negative stain showed no distinct background staining produced by the secondary antibody and $D A B$ reaction. 
**Western blot experiments were performed by collaborators from Lombroso lab and

KCC2 staining by collaborators from De Koninck lab (Dedek et al, Brain, 2019).** 

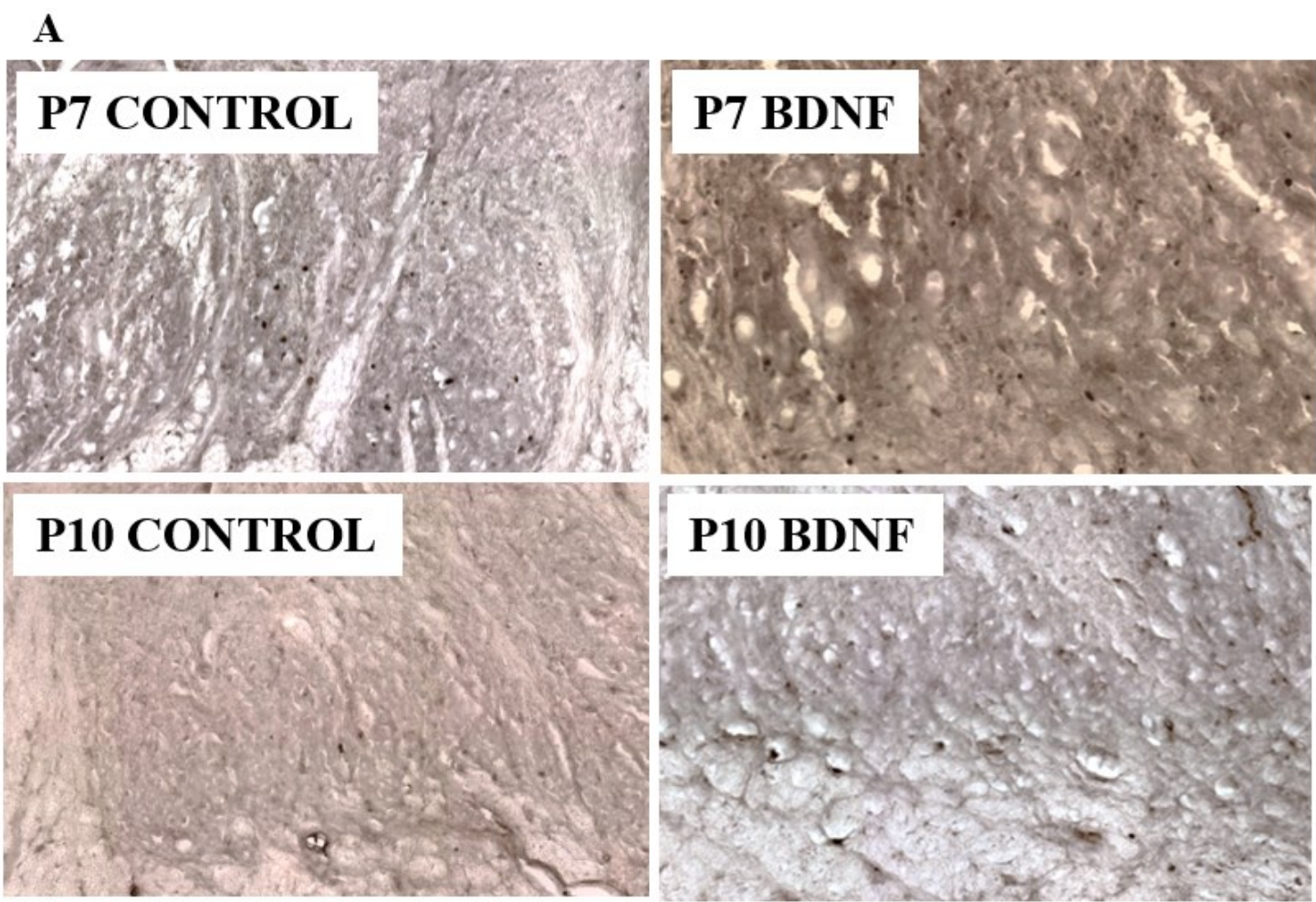

\section{B}
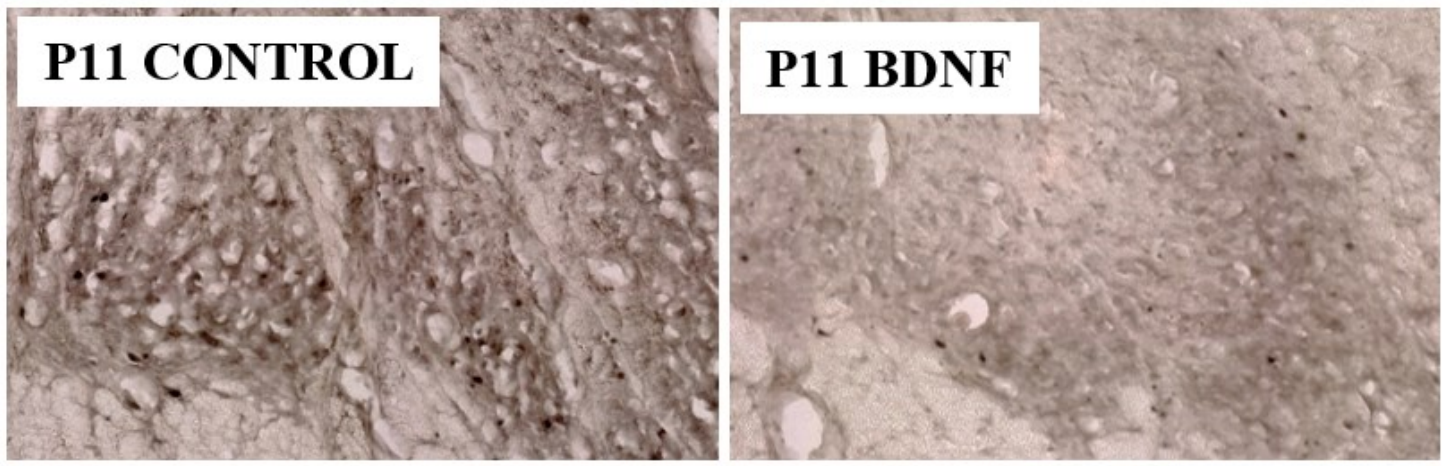

\section{P16 CONTROL}

\section{P16 BDNF}

Figure 10: Representative images show high individual variability in cFos expression in (A) male and (B) female cFos stained BDNF- or saline- treated superficial dorsal horn (20x magnification). 


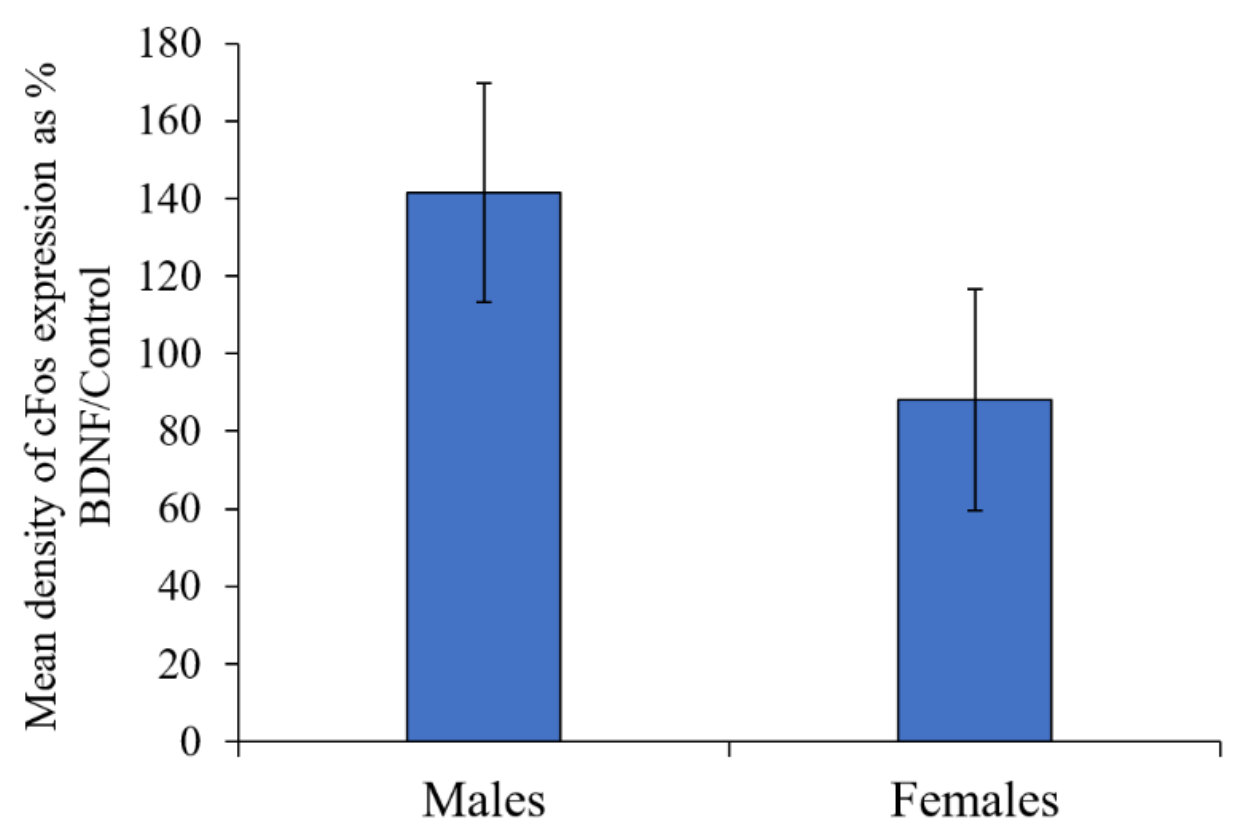

Figure 11: cFos expression increases in BDNF-treated male superficial dorsal horn but not in female BDNF-treated superficial dorsal horn. cfos expression in BDNF-treated cords calculated as a percentage of $\mathrm{cFos}$ expression in saline-treated cords in of $n=8$ human males and $n=6$ human females.

\section{Discussion}

In the present study, we show that ex vivo BDNF treatment to human male spinal cords downregulated KCC2 and STEP 61 and upregulated active Fyn (pFyn) and phosphorylated GluN2B (pGluN2B) at superficial dorsal horn synapses. A large body of evidence show that this pathway is also conserved in male rodents. BDNF released at the superficial dorsal horn during chronic pain conditions bind to TrkB receptors. The resulting disinhibition caused by KCC2 downregulation in conjunction with facilitated excitation caused by potentiation of GluN2BNMDARs results in increased firing of superficial dorsal horn neurons [99]. This BDNF mediated disinhibition-facilitated excitation pathway is conserved across several models of rodent chronic pain including the rodent ex vivo BDNF model, persistent inflammatory pain [84] and chronic nerve injury pain [56]. Our finding suggests that this pathway may be conserved in these pain 
conditions in human males as well, although further experiments such as biochemical analysis on spine donor samples from chronic pain patients and assays to assess whether BDNF levels are elevated in patients with chronic pain must be performed for confirmation. Further, given the important role of $\mathrm{STEP}_{61}$ as the linker between disinhibition and GluN2B-mediated excitation, and its modulatory effects on all the critical elements - TrkB, Fyn and GluN2B - of the BDNF pain pathway $[79,80,82,84,100]$ our observation that $\mathrm{STEP}_{61}$ is also downregulated at the superficial dorsal horn synapses by BDNF in human males similar to male rodents may prompt future pain research to investigate whether modulating active $\mathrm{STEP}_{61}$ levels can change pain hypersensitivity in rodents and if those findings are relevant to humans. This may be a promising avenue as directly manipulating NMDARs and BDNF-TrkB signalling can lead to various pathologies [66, 101-103].

We also show that the BDNF-disinhibition-facilitated excitation pathway is not present in spinal tissue of human females. Our lab has also found that the BDNF pathway is not seen in female rodents in a persistent inflammatory pain model (data not shown). Our human results reinforce that identification of spinal pain targets as well as development of pain medications for chronic pain should not be solely based on male participants, spinal cord donors or rodents. Our findings prove important to bridge the vast translational jump from experimental and clinical pain research.

The prevalence of chronic pain is higher in females than males in clinical settings [104]. Therefore, there is an increased interest in current pain research to identify the mechanisms underlying sex differences observed in chronic pain. Sex differences in opioid analgesics have been studied intensely. In both clinical and experimental studies, morphine has been shown to be more effective in females than males [105]. This finding is supported by other studies showing profound sex differences in neuronal circuits that mediate morphine analgesia in the rat spinal cord 
[106]. The differences in mu and/or kappa opioid heterodimer expression imparts the sex differences in the spinal circuits. The concomitant activation of mu and kappa opioid receptors, which is not seen in male rodents, subserves spinal morphine analgesia in females. The expression of these heterodimers is regulated by spinal estrogen, therefore, these heterodimers are found in higher levels in the female rat spinal cord imparting higher morphine analgesia to females.

Some studies show that sex differences may be complicated in females due to the menstrual cycle, where females have differing sensitivity to pain depending on the levels of hormones during various stages of the cycle $[107,108]$. These findings lead to the possibility that the sex differences seen in pain and analgesia could perhaps be explained by the influence of gonadal hormones, which vary substantially between the sexes. Indeed, gonadal hormones during the development of the organism (organizational effects) as well as during adulthood (activational effects) influence pain and analgesia. Defeminisation of female rat pups by testosterone administration and preventing masculinization of male rat pups have shown to abolish the sex differences in morphine sensitivity observed in normal adults, which is an example of developmental effects of gonadal hormones [109]. Cycle related changes in opioid analgesia in female rodents is an example of activational effects of estradiol [110]. There is also evidence of sex differences in the midbrain-brainstem circuitry that mediate opioid analgesia and hyperalgesia in mice. These findings indicate that there are two pathways that produce the effects of morphine. The circuitry uses NMDARs in males [111, 112] whereas females use melanocortin 1 receptors (MC1R) $[113,114]$. However, females can switch back and forth between the two pathways depending on hormone levels (estrogen or progesterone) $[115,116]$. In addition, BDNF released in the superficial dorsal horn by microglia is part of an immune response only in male neuropathic pain, and immune responses have been shown to be different between sexes in terms of pain pathology [117]. These findings suggest that 
sex hormones may potentially be regulating neuronal signalling in the pain pathways at the superficial dorsal horn.

In the present study, in addition to western blot results we also showed that KCC2 is downregulated in the superficial dorsal horn in human males using immunohistochemistry. Similarly, immunohistochemical experiments showed downregulation of KCC2 in human female spinal cord as well (data not shown). Our western blot results suggest that human females may deviate from the male BDNF pathway in the steps after KCC2 downregulation. Western blots of BDNF treated female superficial dorsal horn showed reduction in KCC2 expression, however, this result was nonsignificant $(\mathrm{p}=0.332)$. KCC2 downregulation in female western blots may have not been significant due to the relatively smaller number of female donors assessed compared to males. Given the variation in age, genetics and other complicating factors between donors, the female western blot results may have been unduly influenced by the small number of female donors. A more robust number of donors would allow us to statistically examine and remove outliers with greater efficiency to validate the western blot results of the female donors. Interestingly, our western blots did not show statistically significant differences between the sexes in any of our molecular targets in the BDNF pathway. Again, due to the difficulty in obtaining a large number of human donors and the great variance in human patients, further investigation is necessary to fully validate these results.

Another factor that should be taken into consideration is that although KCC2 and STEP 61 are neuron-specific, NMDARs and Fyn kinase are present in both neurons and glial cells. Therefore, it is critical to investigate whether the changes in NMDARs and Fyn kinase in our ex vivo human BDNF model are neuron specific using immunohistochemical experiments. However, we have electrophysiological evidence indicating that BDNF potentiates GluN2B-NMDAR 
mediated currents specifically in lamina I neurons in the superficial dorsal horn in live rodent spinal slices $[56,84]$.

One of our important experimental findings is that BDNF treatment resulted in the same changes in the human male and female superficial dorsal horns as seen in rodent chronic pain models regardless of the many uncontrollable variables and other individual differences of these human donors. This increases the validity of our human ex vivo BDNF model and its potential role in spinal pain processing within humans. Further, the observed changes in protein expression and phosphorylation between control and BDNF treatment conditions further confirm that the viability of the tissue is preserved in the human ex vivo model.

In the final part of the study, we developed and refined a cFos staining assay to test whether BDNF increases neuronal activation in human male and female superficial dorsal horns. The trend of increased cFos density at the superficial dorsal horn in the male BDNF group and not seeing this effect in the females is consistent with our western blot results showing the presence of the BDNF pathway only in the males. Increasing the sample sizes for the males and females will show whether this sex difference is significant.

It is also important to further confirm our cFos results using other markers of neuronal excitation. For this purpose, pERK is a potential candidate as pERK is a better marker of paininduced neural excitation compared to cFos [68]. pERK has been shown to be essential in the development and maintenance of central sensitization which underlies chronic pain. In fact, pharmacological inhibition of pERK reduces pain related behaviours whereas cFos suppression has rendered inconsistent results. cFos is only expressed in the nucleus whereas pERK is expressed in the cytoplasm, dendrites and axons in addition to the nucleus. pERK is induced rapidly following a noxious stimulus which correlates better with the development of pain hypersensitivity 
compared to the longer duration taken for cFos induction following painful stimuli. Since cFos activation takes much longer to return to baseline, at the time of fixing the tissue sections, cFos activation that is induced by mechanical stressors during tissue extraction may also be preserved. However, since pERK expression returns to baseline in the span of a few minutes, $p E R K$ seen following BDNF treatment would only be induced by BDNF. Beyond immunohistochemical markers, there are several other techniques that could also be used to directly measure the effects of BDNF on superficial dorsal horn excitability. Voltage sensitive dye imaging (VSDI), which uses the application of voltage sensitive dye molecules to the surface of the tissue allows for visualizing the activity of single neurons or neuronal populations in live tissue with high temporal and spatial resolution [118]. Similarly, multielectrode array recordings can detect overall activation of the superficial dorsal horn neurons [119]. However, the caveat to both these techniques is that the measured signals can be modulated by glial activity. However, the 3-4 second delay in glial cell activation from stimulus onset can be used to distinguish glial activation from neuronal activation [118].

Using the above approaches, it is critical to address how BDNF expression, the molecules of the BDNF pathway and superficial dorsal horn excitability changes across different pain conditions, age and different types of pain management medications. These studies will further our knowledge on spinal mechanisms of human chronic pain and aid us in developing better and more individualized chronic pain treatments. 


\section{$\underline{\text { References }}$}

1. Goldberg DS, McGee SJ. Pain as a global public health priority. BMC Public Health. 2011;11:770. doi:10.1186/1471-2458-11-770.

2. Schopflocher D, Taenzer P, Jovey R. The prevalence of chronic pain in Canada. Pain Res Manag. 2011;16:445-50. http://www.ncbi.nlm.nih.gov/pubmed/22184555.

3. Ballantyne JC, LaForge KS. Opioid dependence and addiction during opioid treatment of chronic pain. Pain. 2007;129:235-55. doi:10.1016/j.pain.2007.03.028.

4. Sostres C, Carrera-Lasfuentes P, Lanas A. Non-steroidal anti-inflammatory drug related upper gastrointestinal bleeding: types of drug use and patient profiles in real clinical practice. Curr Med Res Opin. 2017;33:1815-20. doi:10.1080/03007995.2017.1338178.

5. Phillips CJ, Schopflocher D. The Economics of Chronic Pain. In: Chronic Pain. Weinheim, Germany: Wiley-VCH Verlag GmbH \& Co. KGaA; 2008. p. 41-50. doi:10.1002/9783527622665.ch4.

6. Richardson CG, Chalmers A, Llewellyn-Thomas HA, Klinkhoff A, Carswell A, Kopec JA. Pain relief in osteoarthritis: patients' willingness to risk medication-induced gastrointestinal, cardiovascular, and cerebrovascular complications. J Rheumatol. 2007;34:1569-75. http://www.ncbi.nlm.nih.gov/pubmed/17552039.

7. Edlund MJ, Sullivan MD, Han X, Booth BM. Days with pain and substance use disorders: is there an association? Clin J Pain. 2013;29:689-95. doi:10.1097/AJP.0b013e318270fa77.

8. Sheng J, Liu S, Wang Y, Cui R, Zhang X. The Link between Depression and Chronic Pain: Neural Mechanisms in the Brain. Neural Plast. 2017;2017:9724371. doi:10.1155/2017/9724371.

9. Thornton RG. Considerations in treating patients with chronic pain. Proc (Bayl Univ Med Cent). 2011;24:262-5. http://www.ncbi.nlm.nih.gov/pubmed/21738305.

10. Woolf CJ, Ma Q. Nociceptors--noxious stimulus detectors. Neuron. 2007;55:353-64. doi:10.1016/j.neuron.2007.07.016.

11. von Hehn CA, Baron R, Woolf CJ. Deconstructing the Neuropathic Pain Phenotype to Reveal Neural Mechanisms. Neuron. 2012;73:638-52. doi:10.1016/j.neuron.2012.02.008.

12. Whitten CE, Donovan M, Cristobal K. Treating chronic pain: new knowledge, more choices. Perm J. 2005;9:9-18. http://www.ncbi.nlm.nih.gov/pubmed/22811639.

13. Gangadharan V, Kuner R. Pain hypersensitivity mechanisms at a glance. Dis Model Mech. 2013;6:889-95. doi:10.1242/dmm.011502.

14. Huang J, Zhang X, McNaughton PA. Inflammatory pain: the cellular basis of heat hyperalgesia. Curr Neuropharmacol. 2006;4:197-206. http://www.ncbi.nlm.nih.gov/pubmed/18615146.

15. Price DD, Hu JW, Dubner R, Gracely RH. Peripheral suppression of first pain and central summation of second pain evoked by noxious heat pulses. Pain. 1977;3:57-68. doi:10.1016/0304-3959(77)90035-5. 
16. Campbell JN, LaMotte RH. Latency to detection of first pain. Brain Res. 1983;266:203-8. doi:10.1016/0006-8993(83)90650-9.

17. Leitl MD, Onvani S, Bowers MS, Cheng K, Rice KC, Carlezon WA, et al. Pain-related depression of the mesolimbic dopamine system in rats: expression, blockade by analgesics, and role of endogenous k-opioids. Neuropsychopharmacology. 2014;39:614-24.

doi:10.1038/npp.2013.236.

18. Bras M, Dordević V, Gregurek R, Bulajić M. Neurobiological and clinical relationship between psychiatric disorders and chronic pain. Psychiatr Danub. 2010;22:221-6. http://www.ncbi.nlm.nih.gov/pubmed/20562750.

19. Basbaum AI, Bautista DM, Scherrer G, Julius D. Cellular and Molecular Mechanisms of Pain. Cell. 2009;139:267-84. doi:10.1016/j.cell.2009.09.028.

20. Eftekhari S, Warfvinge K, Blixt FW, Edvinsson L. Differentiation of Nerve Fibers Storing CGRP and CGRP Receptors in the Peripheral Trigeminovascular System. J Pain. 2013;14:1289303. doi:10.1016/j.jpain.2013.03.010.

21. Todd AJ. Neuronal circuitry for pain processing in the dorsal horn. Nat Rev Neurosci. 2010;11:823-36. doi:10.1038/nrn2947.

22. Spike RC, Puskár Z, Andrew D, Todd AJ. A quantitative and morphological study of projection neurons in lamina I of the rat lumbar spinal cord. Eur J Neurosci. 2003;18:2433-48. http://www.ncbi.nlm.nih.gov/pubmed/14622144.

23. Bice TN, Beal JA. Quantitative and neurogenic analysis of neurons with supraspinal projections in the superficial dorsal horn of the rat lumbar spinal cord. J Comp Neurol. 1997;388:565-74. http://www.ncbi.nlm.nih.gov/pubmed/9388016.

24. Latremoliere A, Woolf CJ. Central Sensitization: A Generator of Pain Hypersensitivity by Central Neural Plasticity. J Pain. 2009;10:895-926. doi:10.1016/j.jpain.2009.06.012.

25. Tong C-K, MacDermott AB. Synaptic GluN2A and GluN2B containing NMDA receptors within the superficial dorsal horn activated following primary afferent stimulation. J Neurosci. 2014;34:10808-20.

26. Riedel G. Glutamate receptor function in learning and memory. Behav Brain Res. 2003;140:1-47.

27. Bourinet E, Altier C, Hildebrand ME, Trang T, Salter MW, Zamponi GW. CalciumPermeable Ion Channels in Pain Signaling. Physiol Rev. 2014;94:81-140. doi:10.1152/physrev.00023.2013.

28. Nakanishi S. Molecular diversity of glutamate receptors and implications for brain function. Science. 1992;258:597-603. http://www.ncbi.nlm.nih.gov/pubmed/1329206.

29. Woolf CJ, Thompson SW. The induction and maintenance of central sensitization is dependent on N-methyl-D-aspartic acid receptor activation; implications for the treatment of post-injury pain hypersensitivity states. Pain. 1991;44:293-9.

http://www.ncbi.nlm.nih.gov/pubmed/1828878. 
30. Li J, Simone DA, Larson AA. Windup leads to characteristics of central sensitization. Pain. 1999;79:75-82. http://www.ncbi.nlm.nih.gov/pubmed/9928779.

31. Woolf CJ. Central sensitization: Implications for the diagnosis and treatment of pain. Pain. 2011;152 Supplement:S2-15. doi:10.1016/j.pain.2010.09.030.

32. Yan X, Jiang E, Gao M, Weng H-R. Endogenous activation of presynaptic NMDA receptors enhances glutamate release from the primary afferents in the spinal dorsal horn in a rat model of neuropathic pain. J Physiol. 2013;591:2001-19. doi:10.1113/jphysiol.2012.250522.

33. Du J, Zhou S, Coggeshall R., Carlton S. N-methyl-d-aspartate-induced excitation and sensitization of normal and inflamed nociceptors. Neuroscience. 2003;118:547-62. doi:10.1016/S0306-4522(03)00009-5.

34. Nagy GG, Watanabe M, Fukaya M, Todd AJ. Synaptic distribution of the NR1, NR2A and NR2B subunits of the N-methyl-d-aspartate receptor in the rat lumbar spinal cord revealed with an antigen-unmasking technique. Eur J Neurosci. 2004;20:3301-12. doi:10.1111/j.14609568.2004.03798.x.

35. Hildebrand ME, Pitcher GM, Harding EK, Li H, Beggs S, Salter MW. GluN2B and GluN2D NMDARs dominate synaptic responses in the adult spinal cord. Sci Rep. 2014;4. doi:10.1038/srep04094.

36. Abe T, Matsumura S, Katano T, Mabuchi T, Takagi K, Xu L, et al. Fyn kinase-mediated phosphorylation of NMDA receptor NR2B subunit at Tyr1472 is essential for maintenance of neuropathic pain. Eur J Neurosci. 2005;22:1445-54. doi:10.1111/j.1460-9568.2005.04340.x.

37. Liu XJ, Gingrich JR, Vargas-Caballero M, Dong YN, Sengar A, Beggs S, et al. Treatment of inflammatory and neuropathic pain by uncoupling Src from the NMDA receptor complex. Nat Med. 2008;14:1325-32. doi:10.1038/nm.1883.

38. Carreño FR, Walch JD, Dutta M, Nedungadi TP, Cunningham JT. Brain-derived neurotrophic factor-tyrosine kinase B pathway mediates NMDA receptor NR2B subunit phosphorylation in the supraoptic nuclei following progressive dehydration. J Neuroendocrinol. 2011;23:894-905. doi:10.1111/j.1365-2826.2011.02209.x.

39. Xu F, Plummer MR, Len G-W, Nakazawa T, Yamamoto T, Black IB, et al. Brain-derived neurotrophic factor rapidly increases NMDA receptor channel activity through Fyn-mediated phosphorylation. Brain Res. 2006;1121:22-34. doi:10.1016/j.brainres.2006.08.129.

40. Chen B-S, Roche KW. Regulation of NMDA receptors by phosphorylation.

Neuropharmacology. 2007;53:362-8.

41. Yu XM, Askalan R, Keil GJ, Salter MW. NMDA channel regulation by channel-associated protein tyrosine kinase Src. Science. 1997;275:674-8.

42. Wang YT, Salter MW. Regulation of NMDA receptors by tyrosine kinases and phosphatases. Nature. 1994;369:233-5.

43. Mannion RJ, Costigan M, Decosterd I, Amaya F, Ma QP, Holstege JC, et al. Neurotrophins: peripherally and centrally acting modulators of tactile stimulus-induced inflammatory pain hypersensitivity. Proc Natl Acad Sci U S A. 1999;96:9385-90. 
http://www.ncbi.nlm.nih.gov/pubmed/10430952.

44. Shen H, Chung JM, Chung K. Expression of neurotrophin mRNAs in the dorsal root ganglion after spinal nerve injury. Mol Brain Res. 1999;64:186-92. doi:10.1016/S0169328X(98)00314-3.

45. Theodosiou M, Rush AR, Zhou FX, Hu D, Walker SJ, Tracey JD. Hyperalgesia due to nerve damage: role of nerve growth factor. Pain. 1999;81:245-55. doi:10.1016/S0304-3959(99)000184.

46. Zhou X-F, Chie ET, Deng Y-S, Zhong J-H, Xue Q, Rush RA, et al. Injured primary sensory neurons switch phenotype for brain-derived neurotrophic factor in the rat. Neuroscience.

1999;92:841-53. doi:10.1016/S0306-4522(99)00027-5.

47. Melemedjian OK, Tillu D V, Asiedu MN, Mandell EK, Moy JK, Blute VM, et al. BDNF regulates atypical $\mathrm{PKC}$ at spinal synapses to initiate and maintain a centralized chronic pain state. Mol Pain. 2013;9:12. doi:10.1186/1744-8069-9-12.

48. Obata K, Noguchi K. BDNF in sensory neurons and chronic pain. Neurosci Res. 2006;55:110. doi:10.1016/j.neures.2006.01.005.

49. Zhao J, Seereeram A, Nassar MA, Levato A, Pezet S, Hathaway G, et al. Nociceptor-derived brain-derived neurotrophic factor regulates acute and inflammatory but not neuropathic pain. Mol Cell Neurosci. 2006;31:539-48. doi:10.1016/j.mcn.2005.11.008.

50. Ernfors P, Wetmore C, Olson L, Persson H. Identification of cells in rat brain and peripheral tissues expressing mRNA for members of the nerve growth factor family. Neuron. 1990;5:51126. doi:10.1016/0896-6273(90)90090-3.

51. Lever IJ, Bradbury EJ, Cunningham JR, Adelson DW, Jones MG, McMahon SB, et al. Brain-derived neurotrophic factor is released in the dorsal horn by distinctive patterns of afferent fiber stimulation. J Neurosci. 2001;21:4469-77.

http://www.ncbi.nlm.nih.gov/pubmed/11404434.

52. Pezet S. Noxious Stimulation Induces Trk Receptor and Downstream ERK Phosphorylation in Spinal Dorsal Horn. Mol Cell Neurosci. 2002;21:684-95. doi:10.1006/mcne.2002.1205.

53. Sorge RE, Mapplebeck JCS, Rosen S, Beggs S, Taves S, Alexander JK, et al. Different immune cells mediate mechanical pain hypersensitivity in male and female mice. Nat Neurosci. 2015;18:1081-3. doi:10.1038/nn.4053.

54. Yajima Y, Narita M, Narita M, Matsumoto N, Suzuki T. Involvement of a spinal brainderived neurotrophic factor/full-length TrkB pathway in the development of nerve injuryinduced thermal hyperalgesia in mice. Brain Res. 2002;958:338-46. doi:10.1016/S00068993(02)03666-1.

55. Sikandar S, Minett MS, Millet Q, Santana-Varela S, Lau J, Wood JN, et al. Brain-derived neurotrophic factor derived from sensory neurons plays a critical role in chronic pain. Brain. 2018;141:1028-39.

56. Hildebrand ME, Xu J, Dedek A, Li Y, Sengar AS, Beggs S, et al. Potentiation of Synaptic GluN2B NMDAR Currents by Fyn Kinase Is Gated through BDNF-Mediated Disinhibition in 
Spinal Pain Processing. Cell Rep. 2016;17:2753-65. doi:10.1016/j.celrep.2016.11.024.

57. Geng S-J, Liao F-F, Dang W-H, Ding X, Liu X-D, Cai J, et al. Contribution of the spinal cord BDNF to the development of neuropathic pain by activation of the NR2B-containing NMDA receptors in rats with spinal nerve ligation. Exp Neurol. 2010;222:256-66. doi:10.1016/j.expneurol.2010.01.003.

58. Moy JK, Szabo-Pardi T, Tillu D V., Megat S, Pradhan G, Kume M, et al. Temporal and sex differences in the role of $\mathrm{BDNF} / \mathrm{TrkB}$ signaling in hyperalgesic priming in mice and rats. Neurobiol Pain. 2019;5:100024. doi:10.1016/j.ynpai.2018.10.001.

59. Rivera C, Li H, Thomas-Crusells J, Lahtinen H, Viitanen T, Nanobashvili A, et al. BDNFinduced TrkB activation down-regulates the $\mathrm{K}+-\mathrm{Cl}$ - cotransporter $\mathrm{KCC} 2$ and impairs neuronal Cl- extrusion. J Cell Biol. 2002;159:747-52. doi:10.1083/jcb.200209011.

60. Rivera C, Voipio J, Thomas-Crusells J, Li H, Emri Z, Sipilä S, et al. Mechanism of activitydependent downregulation of the neuron-specific K-Cl cotransporter KCC2. J Neurosci. 2004;24:4683-91. doi:10.1523/JNEUROSCI.5265-03.2004.

61. Zhang W, Liu L-Y, Xu T-L. Reduced potassium-chloride co-transporter expression in spinal cord dorsal horn neurons contributes to inflammatory pain hypersensitivity in rats. Neuroscience. 2008;152:502-10. doi:10.1016/j.neuroscience.2007.12.037.

62. Coull JAM, Boudreau D, Bachand K, Prescott SA, Nault F, Sík A, et al. Trans-synaptic shift in anion gradient in spinal lamina I neurons as a mechanism of neuropathic pain. Nature. 2003;424:938-42. doi:10.1038/nature01868.

63. Price TJ, Cervero F, de Koninck Y. Role of cation-chloride-cotransporters (CCC) in pain and hyperalgesia. Curr Top Med Chem. 2005;5:547-55. http://www.ncbi.nlm.nih.gov/pubmed/16022677.

64. Delpire E. Cation-Chloride Cotransporters in Neuronal Communication. News Physiol Sci. 2000;15:309-12. http://www.ncbi.nlm.nih.gov/pubmed/11390932.

65. Mantyh PW, Hunt SP. Setting the tone: superficial dorsal horn projection neurons regulate pain sensitivity. Trends Neurosci. 2004;27:582-4. doi:10.1016/j.tins.2004.07.007.

66. Kahle KT, Khanna A, Clapham DE, Woolf CJ. Therapeutic restoration of spinal inhibition via druggable enhancement of potassium-chloride cotransporter KCC2-mediated chloride extrusion in peripheral neuropathic pain. JAMA Neurol. 2014;71:640-5.

doi:10.1001/jamaneurol.2014.21.

67. Gagnon M, Bergeron MJ, Lavertu G, Castonguay A, Tripathy S, Bonin RP, et al. Chloride extrusion enhancers as novel therapeutics for neurological diseases. Nat Med. 2013;19:1524-8. doi: $10.1038 / \mathrm{nm} .3356$.

68. Gao Y-J, Ji R-R. c-Fos and pERK, which is a better marker for neuronal activation and central sensitization after noxious stimulation and tissue injury? Open Pain J. 2009;2:11-7. doi:10.2174/1876386300902010011.

69. Abbadie C, Honoré P, Besson JM. Intense cold noxious stimulation of the rat hindpaw induces c-fos expression in lumbar spinal cord neurons. Neuroscience. 1994;59:457-68. 
http://www.ncbi.nlm.nih.gov/pubmed/8008200.

70. Traub RJ, Pechman P, Iadarola MJ, Gebhart GF. Fos-like proteins in the lumbosacral spinal cord following noxious and non-noxious colorectal distention in the rat. Pain. 1992;49:393-403. http://www.ncbi.nlm.nih.gov/pubmed/1408305.

71. Bester H, Beggs S, Woolf CJ. Changes in tactile stimuli-induced behavior and c-Fos expression in the superficial dorsal horn and in parabrachial nuclei after sciatic nerve crush. $\mathrm{J}$ Comp Neurol. 2000;428:45-61. http://www.ncbi.nlm.nih.gov/pubmed/11058224.

72. Ma QP, Woolf CJ. Basal and touch-evoked fos-like immunoreactivity during experimental inflammation in the rat. Pain. 1996;67:307-16. http://www.ncbi.nlm.nih.gov/pubmed/8951924.

73. Fitzpatrick CJ, Lombroso PJ. The Role of Striatal-Enriched Protein Tyrosine Phosphatase (STEP) in Cognition. Front Neuroanat. 2011;5:47. doi:10.3389/fnana.2011.00047.

74. Carty NC, Xu J, Kurup P, Brouillette J, Goebel-Goody SM, Austin DR, et al. The tyrosine phosphatase STEP: implications in schizophrenia and the molecular mechanism underlying antipsychotic medications. Transl Psychiatry. 2012;2:e137. doi:10.1038/tp.2012.63.

75. Kurup PK, Xu J, Videira RA, Ononenyi C, Baltazar G, Lombroso PJ, et al. STEP61 is a substrate of the E3 ligase parkin and is upregulated in Parkinson's disease. Proc Natl Acad Sci U S A. 2015;112:1202-7. doi:10.1073/pnas.1417423112.

76. Zhang Y, Kurup P, Xu J, Carty N, Fernandez SM, Nygaard HB, et al. Genetic reduction of striatal-enriched tyrosine phosphatase (STEP) reverses cognitive and cellular deficits in an Alzheimer's disease mouse model. Proc Natl Acad Sci U S A. 2010;107:19014-9. doi:10.1073/pnas.1013543107.

77. Kurup P, Zhang Y, Xu J, Venkitaramani D V, Haroutunian V, Greengard P, et al. Abetamediated NMDA receptor endocytosis in Alzheimer's disease involves ubiquitination of the tyrosine phosphatase STEP61. J Neurosci. 2010;30:5948-57. doi:10.1523/JNEUROSCI.015710.2010 .

78. Snyder EM, Nong Y, Almeida CG, Paul S, Moran T, Choi EY, et al. Regulation of NMDA receptor trafficking by amyloid-beta. Nat Neurosci. 2005;8:1051-8. doi:10.1038/nn1503.

79. Nguyen T-H, Liu J, Lombroso PJ. Striatal enriched phosphatase 61 dephosphorylates Fyn at phosphotyrosine 420. J Biol Chem. 2002;277:24274-9. doi:10.1074/jbc.M111683200.

80. Xu J, Kurup P, Foscue E, Lombroso PJ. Striatal-enriched protein tyrosine phosphatase regulates the PTP $\alpha /$ Fyn signaling pathway. J Neurochem. 2015;134:629-41.

doi:10.1111/jnc.13160.

81. Saavedra A, Puigdellívol M, Tyebji S, Kurup P, Xu J, Ginés S, et al. BDNF Induces StriatalEnriched Protein Tyrosine Phosphatase 61 Degradation Through the Proteasome. Mol Neurobiol. 2016;53:4261-73. doi:10.1007/s12035-015-9335-7.

82. Azkona G, Saavedra A, Aira Z, Aluja D, Xifró X, Baguley T, et al. Striatal-enriched protein tyrosine phosphatase modulates nociception: evidence from genetic deletion and pharmacological inhibition. Pain. 2016;157:377-86. doi:10.1097/j.pain.0000000000000329. 
83. Xu J, Kurup P, Foscue E, Lombroso PJ. Striatal-enriched protein tyrosine phosphatase regulates the PTP $\alpha /$ Fyn signaling pathway. J Neurochem. 2015;134:629-41.

doi:10.1111/jnc. 13160.

84. Dedek A, Xu J, Kandegedara CM, Lorenzo L-É, Godin AG, De Koninck Y, et al. Loss of STEP61 couples disinhibition to N-methyl-d-aspartate receptor potentiation in rodent and human spinal pain processing. Brain. 2019;142:1535-46. doi:10.1093/brain/awz105.

85. Gereau RW, Sluka KA, Maixner W, Savage SR, Price TJ, Murinson BB, et al. A pain research agenda for the 21st century. J Pain. 2014;15:1203-14.

86. Del Valle L, Schwartzman RJ, Alexander G. Spinal cord histopathological alterations in a patient with longstanding complex regional pain syndrome. Brain Behav Immun. 2009;23:8591. doi:10.1016/j.bbi.2008.08.004.

87. Shi Y, Gelman BB, Lisinicchia JG, Tang S-J. Chronic-Pain-Associated Astrocytic Reaction in the Spinal Cord Dorsal Horn of Human Immunodeficiency Virus-Infected Patients. J Neurosci. 2012;32:10833-40. doi:10.1523/JNEUROSCI.5628-11.2012.

88. Shcheglovitov A, Shcheglovitova O, Yazawa M, Portmann T, Shu R, Sebastiano V, et al. SHANK3 and IGF1 restore synaptic deficits in neurons from 22q13 deletion syndrome patients. Nature. 2013;503:267-71. doi:10.1038/nature12618.

89. Lieberman R, Levine ES, Kranzler HR, Abreu C, Covault J. Pilot study of iPS-derived neural cells to examine biologic effects of alcohol on human neurons in vitro. Alcohol Clin Exp Res. 2012;36:1678-87. doi:10.1111/j.1530-0277.2012.01792.x.

90. Zhang W-B, Ross PJ, Tu Y, Wang Y, Beggs S, Sengar AS, et al. Fyn Kinase regulates GluN2B subunit-dominant NMDA receptors in human induced pluripotent stem cell-derived neurons. Sci Rep. 2016;6:23837. doi:10.1038/srep23837.

91. Coull JAM, Beggs S, Boudreau D, Boivin D, Tsuda M, Inoue K, et al. BDNF from microglia causes the shift in neuronal anion gradient underlying neuropathic pain. Nature. $2005 ; 438: 1017-$ 21. doi:10.1038/nature04223.

92. Li L, Chen S-R, Chen H, Wen L, Hittelman WN, Xie J-D, et al. Chloride Homeostasis Critically Regulates Synaptic NMDA Receptor Activity in Neuropathic Pain. Cell Rep. 2016;15:1376-83.

93. Lee KY, Prescott SA. Chloride dysregulation and inhibitory receptor blockade yield equivalent disinhibition of spinal neurons yet are differentially reversed by carbonic anhydrase blockade. Pain. 2015;156:2431-7.

94. Katsura H, Obata K, Mizushima T, Sakurai J, Kobayashi K, Yamanaka H, et al. Activation of Src-family kinases in spinal microglia contributes to mechanical hypersensitivity after nerve injury. J Neurosci. 2006;26:8680-90.

95. Liu YN, Yang X, Suo ZW, Xu YM, Hu XD. Fyn kinase-regulated NMDA receptor- and AMPA receptor-dependent pain sensitization in spinal dorsal horn of mice. Eur J Pain. 2014;18:1120-8.

96. Matsumura S, Kunori S, Mabuchi T, Katano T, Nakazawa T, Abe T, et al. Impairment of 
CaMKII activation and attenuation of neuropathic pain in mice lacking NR2B phosphorylated at Tyr1472. Eur J Neurosci. 2010;32:798-810.

97. Kim Y, Cho H, Ahn YJ, Kim J, Yoon YW. Effect of NMDA NR2B antagonist on neuropathic pain in two spinal cord injury models. Pain. 2012;153:1022-9.

98. Averill S, McMahon SB, Clary DO, Reichardt LF, Priestley J V. Immunocytochemical localization of trkA receptors in chemically identified subgroups of adult rat sensory neurons. Eur J Neurosci. 1995;7:1484-94. http://www.ncbi.nlm.nih.gov/pubmed/7551174.

99. Keller AF, Beggs S, Salter MW, De Koninck Y. Transformation of the output of spinal lamina I neurons after nerve injury and microglia stimulation underlying neuropathic pain. Mol Pain. 2007;3:27. doi:10.1186/1744-8069-3-27.

100. Xu J, Kurup P, Baguley TD, Foscue E, Ellman JA, Nairn AC, et al. Inhibition of the tyrosine phosphatase STEP61 restores BDNF expression and reverses motor and cognitive deficits in phencyclidine-treated mice. Cell Mol Life Sci. 2016;73:1503-14. doi:10.1007/s00018015-2057-1.

101. Lindholm JSO, Castrén E. Mice with altered BDNF signaling as models for mood disorders and antidepressant effects. Front Behav Neurosci. 2014;8:143. doi:10.3389/fnbeh.2014.00143.

102. Petrone A, Battaglia F, Wang C, Dusa A, Su J, Zagzag D, et al. Receptor protein tyrosine phosphatase alpha is essential for hippocampal neuronal migration and long-term potentiation. EMBO J. 2003;22:4121-31. doi:10.1093/emboj/cdg399.

103. Skelton MR, Ponniah S, Wang DZ-M, Doetschman T, Vorhees C V, Pallen CJ. Protein tyrosine phosphatase alpha (PTP alpha) knockout mice show deficits in Morris water maze learning, decreased locomotor activity, and decreases in anxiety. Brain Res. 2003;984:1-10. http://www.ncbi.nlm.nih.gov/pubmed/12932834.

104. Mogil JS. Sex differences in pain and pain inhibition: multiple explanations of a controversial phenomenon. Nat Rev Neurosci. 2012;13:859-66. doi:10.1038/nrn3360.

105. Niesters M, Dahan A, Kest B, Zacny J, Stijnen T, Aarts L, et al. Do sex differences exist in opioid analgesia? A systematic review and meta-analysis of human experimental and clinical studies. Pain. 2010;151:61-8. doi:10.1016/j.pain.2010.06.012.

106. Chakrabarti S, Liu N-J, Gintzler AR. Formation of mu-/kappa-opioid receptor heterodimer is sex-dependent and mediates female-specific opioid analgesia. Proc Natl Acad Sci U S A. 2010;107:20115-9. doi:10.1073/pnas.1009923107.

107. Riley JL, Robinson ME, Wise EA, Price DD. A meta-analytic review of pain perception across the menstrual cycle. Pain. 1999;81:225-35.

http:/www.ncbi.nlm.nih.gov/pubmed/10431710.

108. Martin VT. Ovarian hormones and pain response: a review of clinical and basic science studies. Gend Med. 2009;6 Suppl 2:168-92. doi:10.1016/j.genm.2009.03.006.

109. Cicero TJ, Nock B, O’Connor L, Meyer ER. Role of steroids in sex differences in morphine-induced analgesia: activational and organizational effects. J Pharmacol Exp Ther. 2002;300:695-701. doi:10.1124/jpet.300.2.695. 
110. Craft RM, Mogil JS, Aloisi AM. Sex differences in pain and analgesia: the role of gonadal hormones. Eur J Pain. 2004;8:397-411. doi:10.1016/j.ejpain.2004.01.003.

111. Sternberg WF. Sex differences in the effects of prenatal stress on stress-induced analgesia. Physiol Behav. 1999;68:63-72. http://www.ncbi.nlm.nih.gov/pubmed/10627063.

112. Bryant CD, Eitan S, Sinchak K, Fanselow MS, Evans CJ. NMDA receptor antagonism disrupts the development of morphine analgesic tolerance in male, but not female C57BL/6J mice. Am J Physiol Regul Integr Comp Physiol. 2006;291:R315-26. doi:10.1152/ajpregu.00831.2005.

113. Mogil JS, Wilson SG, Chesler EJ, Rankin AL, Nemmani KVS, Lariviere WR, et al. The melanocortin-1 receptor gene mediates female-specific mechanisms of analgesia in mice and humans. Proc Natl Acad Sci U S A. 2003;100:4867-72. doi:10.1073/pnas.0730053100.

114. Juni A, Cai M, Stankova M, Waxman AR, Arout C, Klein G, et al. Sex-specific mediation of opioid-induced hyperalgesia by the melanocortin-1 receptor. Anesthesiology. 2010;112:1818. doi:10.1097/ALN.0b013e3181c53849.

115. Kavaliers M, Galea LA. Sex differences in the expression and antagonism of swim stressinduced analgesia in deer mice vary with the breeding season. Pain. 1995;63:327-34. http://www.ncbi.nlm.nih.gov/pubmed/8719533.

116. Mogil JS, Sternberg WF, Kest B, Marek P, Liebeskind JC. Sex differences in the antagonism of swim stress-induced analgesia: effects of gonadectomy and estrogen replacement. Pain. 1993;53:17-25. http://www.ncbi.nlm.nih.gov/pubmed/8316385.

117. Sorge RE, LaCroix-Fralish ML, Tuttle AH, Sotocinal SG, Austin J-S, Ritchie J, et al. Spinal cord Toll-like receptor 4 mediates inflammatory and neuropathic hypersensitivity in male but not female mice. J Neurosci. 2011;31:15450-4. doi:10.1523/JNEUROSCI.3859-11.2011.

118. Chemla S, Chavane F. Voltage-sensitive dye imaging: Technique review and models. J Physiol. 2010;104:40-50. doi:10.1016/j.jphysparis.2009.11.009.

119. Obien MEJ, Deligkaris K, Bullmann T, Bakkum DJ, Frey U. Revealing neuronal function through microelectrode array recordings. Front Neurosci. 2014;8:423. doi:10.3389/fnins.2014.00423. 